\title{
Anatomia foliar de Eugenia brasiliensis Lam. (Myrtaceae) proveniente de áreas de restinga e de floresta
}

\author{
Ana Maria Donato ${ }^{1 *}$, Berta Lange de Morretes $^{2}$ \\ ${ }^{1}$ Departamento de Biologia Vegetal, Universidade do Estado do Rio de Janeiro, Rua São Francisco Xavier 524, \\ 20550-013, Rio de Janeiro, RJ, Brasil, \\ ${ }^{2}$ Departamento de Botânica, Instituto de Biociências, Universidade de São Paulo, Rua do Matão, Travessa 14 \\ $n^{\circ}$ 321, Cidade Universitária, 05508-900, São Paulo, SP, Brasil
}

\begin{abstract}
RESUMO: O presente trabalho apresenta a anatomia foliar de Eugenia brasiliensis Lam., cujo óleo essencial possui propriedades anti-reumática, diurética, anti-inflamatória, além de ser ativo contra o Tripanosoma cruzi. O estudo foi feito, comparando-se folhas coletadas em áreas de restinga e de floresta, registrando-se as diferenças estruturais resultantes da influência dos fatores ambientais. Anatomicamente, a folha de E. brasiliensis é hipostomática, glabra, dorsiventral, com tendência à isobilateralidade. A epiderme apresenta notável espessamento da cutícula e seus estratos. Em posição subepidérmica, ocorrem numerosas cavidades secretoras de óleos essenciais, nas duas faces da lâmina foliar. No parênquima lacunoso situam-se drusas de oxalato de cálcio. As folhas provenientes da restinga apresentam, em relação àquelas coletadas na floresta, maior quantidade de estruturas secretoras de óleos essenciais, maior concentração de substâncias ergásticas, maior espessamento da cutícula e da lâmina foliar, maior quantidade de estômatos, mesofilo mais compacto, fibras esclerenquimáticas e elementos xilemáticos com maior grau de lignificação e maior densidade da rede vascular. Os dados obtidos são indicativos que a escolha do local de coleta de E. brasiliensis é relevante, tendo em vista que, na área da restinga, observa-se maior produção de óleos essenciais e demais substâncias associadas aos seus efeitos terapêuticos.
\end{abstract}

Unitermos: Eugenia brasiliensis, Myrtaceae, plantas medicinais, farmacobotânica, anatomia foliar.

\begin{abstract}
Foliar anatomy of Eugenia brasiliensis Lam. (Myrtaceae) from restinga and forest areas". The present paper presents the foliar anatomy of Eugenia brasiliensis Lam. The essential oils produced by this species present anti-reumathic, diuretic and anti-inflammatory properties and show activity against Tripanosoma cruzi. This study was carried out by comparison between leaves developed in restinga and forest areas, in order to register the main differences in the structure of this organ related to environmental conditions. Anatomically, the leaf of $E$. brasiliensis is hipostomatic, glabrous, with dorsiventral mesophyll, whit tendency towards the isobilateral type. Thickness of the cuticle and cutinized wall is noteworthy. In sub-epidermical position, there are many secretory cavities that produce essential oils, in both sides of the foliar blade. In the spongy parenchyma there are calcium oxalate druses crystals. E. brasiliensis leaves developed in restinga area present, in relation to that proceeding from forest, a larger amount of secretory structures, a higher ergastic substances concentration, thicker cuticle and foliar blade, more abundant stomata, a more compact mesophyll, sclerenchyma fibers and xilem elements with a deeper lignification and a greater development of the vascular system. The data obtained in this research suggest that the choice of the area where $E$. brasiliensis should be collected is important, because in restinga area it presents a greater production of essential oils and other substances associated with therapeutic effects.
\end{abstract}

Keywords: Eugenia brasiliensis, Myrtaceae, medicinal plants, pharmacobotany, foliar anatomy.

\section{INTRODUÇÃO}

A utilização de diversas espécies de plantas para fins medicinais é tão antiga quanto a própria história da humanidade (Ezequiel, 47,12; Moreira, 1978; Tyrrel,1990). O conhecimento relacionado aos fitoterápicos vem se ampliando, com a contribuição dos estudos desenvolvidos em várias áreas da ciência. Entre estas, a Anatomia Vegetal contribui com informações que podem subsidiar o controle de qualidade de fármacos de origem vegetal, de grande valia quando as plantas são comercializadas e/ou utilizadas in natura (Duarte; Menarim, 2006; Leite et al., 2007; Scopel et al., 2007).

A espécie selecionada para estudo, Eugenia 
brasiliensis Lam., vulgarmente conhecida como "grumixama”, pertence à família Myrtaceae, a qual é constituída por plantas que apresentam folhas simples, geralmente opostas, com margens inteiras, de coloração sempre verde (Barroso et al., 1984). Segundo Dahlgren; Thorne (1984), a família apresenta cerca de 145 gêneros e mais de 3650 espécies. Eugenia é um dos maiores gêneros e suas espécies encontram-se dispersas nos trópicos e subtrópicos (Airy-Shaw; Willis’s, 1973). Uma das características marcantes da família Myrtaceae é a presença, em seus órgãos vegetativos e reprodutivos, de estruturas secretoras de óleos essenciais (Metcalfe; Chalk, 1950; Cronquist, 1981; Barroso et al., 1984). Estes são citados por diversos autores como sendo os responsáveis por determinadas propriedades medicinais encontradas nos vegetais (Fevereiro, 1996; Menezesde-Lima Jr. et al., 1997; Siani; Branquinho, 1997; Souza et al., 1998). Segundo Pio Corrêa (1984), E. brasiliensis é uma espécie que apresenta casca e folhas aromáticas, adstringentes, anti-reumáticas e diuréticas. A floração ocorre em setembro/outubro, durando uma ou duas semanas, seguindo-se a formação dos frutos, comestíveis e agradáveis. Menezes-de-Lima Jr. et al. (1997) citam a espécie como interessante do ponto de vista químico e farmacológico, devido ao seu óleo essencial apresentar reação positiva em testes anti-inflamatórios. Segundo Fernandez-Ferreira et al. (1997), o óleo essencial de E. brasiliensis apresenta, ainda, atividade contra o Tripanosoma cruzi.

Este trabalho teve por objetivo caracterizar, anatomicamente, as folhas de E. brasiliensis, que são as partes utilizadas para fins terapêuticos. O estudo foi feito de forma comparativa entre amostras coletadas em ambientes de restinga e de floresta, com o intuito de analisar as diferenças estruturais na anatomia foliar, decorrentes dos fatores ambientais, e a importância da escolha do local de coleta, visando à obtenção do maior rendimento de seus efeitos terapêuticos.

\section{MATERIAL E MÉTODOS}

O material estudado foi coletado em dois ambientes distintos: no Bosque da Barra, uma área remanescente de restinga, situada ao nível do mar, à Av. das Américas, $\mathrm{n}^{\circ}$ 6000, km 7, município do Rio de Janeiro, RJ, e na Floresta da Tijuca, com altitude aproximada de 330 metros, na Estrada da Vista Chinesa, próximo ao $\mathrm{km} \mathrm{3}$, município do Rio de Janeiro, RJ. O primeiro ambiente caracteriza-se por apresentar solo predominantemente arenoso, e vegetação de pequeno porte, constituída, principalmente, por pequenos arbustos e arvoretas esparsos, expostos a uma alta incidência luminosa. A Floresta da Tijuca, por outro lado, pertence à Mata Atlântica e caracteriza-se por apresentar temperaturas mais amenas, luminosidade menos intensa no seu interior, devido ao sombreamento realizado pelos dosséis mais altos, além de um maior teor de umidade.
Machado (1992) menciona as matas do Parque Nacional da Tijuca, como pertencentes à classe de formação de floresta ombrófila densa. Na restinga, os indivíduos de E. brasiliensis recebem a luz solar diretamente, pois não há, nas proximidades, estratos de vegetação mais altos e seu porte é arbustivo, com cerca de 1,70 a 2,0 metros de altura. Na mata, os exemplares observados têm altura de pequenas árvores, com, aproximadamente, 6,5 a 10 metros de altura, e a luz que os atinge é filtrada pelos dosséis mais altos da vegetação. Foram preparadas exsicatas dos exemplares estudados, as quais encontramse depositadas no Herbário da Universidade de São Paulo, USP, com o número de registro SPF 155.529 e no Herbário da Universidade do Estado do Rio de Janeiro, UERJ, com o registro HRJ 9942.

As folhas coletadas para o estudo anatômico foram fixadas em FAA, com graduação alcoólica de $70^{\circ}$ GL, por 48 horas, sendo estocadas, posteriormente, em etanol $70^{\circ}$ GL (Johansen, 1940). Para a determinação da forma do limbo foliar, comparou-se o material estudado com os padrões apresentados por Oliveira; Akissue (1989). As lâminas semipermanentes foram confeccionadas a partir de cortes obtidos à mão livre. A coloração das secções transversais da lâmina foliar e do pecíolo em seu terço médio, foi feita com solução de azul de astra e safranina, ambas a 1\%, em água, na proporção de 9:1 (Bukatsch, 1972).

As epidermes dissociadas pelo método de Jeffrey foram coradas com safranina aquosa e hidroalcoólica (Johansen, l.c.). A diafanização e a coloração de folhas inteiras foram realizadas, segundo a técnica de Foster (1949) e o padrão de venação foliar foi determinado, de acordo com a classificação de Hickey (1979). Para calcular a freqüência média das estruturas secretoras subepidérmicas, foram examinados 25 campos ópticos de secções paradérmicas adjacentes à epiderme das faces adaxial e abaxial das folhas, realizando-se a contagem e o cálculo da média aritmética. $\mathrm{O}$ mesmo procedimento foi utilizado para a contagem dos estômatos. Os dados foram comparados estatisticamente, utilizando-se 0 teste $t$ de Student (Vieira, 1983), estabelecendo-se o nível de significância de $5 \%$.

Secções histológicas obtidas de material fresco foram submetidas a testes histoquímicos.

Para localizar compostos pécticos, utilizou-se o vermelho de rutênio (Johansen, 1940).

Os grãos de amido, taninos e lipídios foram identificados pelo emprego, respectivamente, de lugol, solução de sais de ferro e Sudan IV (Johansen, l.c.).

Glicídios redutores foram localizados com o reagente de Benedict (McLean; Ivimey Cook, 1958).

A natureza química dos cristais foi analisada através de sua solubilidade em ácidos (Howarth; Warne, 1959).

O teste para lignina foi efetuado, utilizando-se floroglucina e ácido hidroclórico (Johansen, l.c.). 
As secções anatômicas foram registradas em fotomicrografias, com o auxílio de microscópio ótico Carl Zeiss Jena, acoplado à máquina fotográfica. Para as medidas das estruturas anatômicas foi utilizada uma ocular micrométrica devidamente aferida com lâmina contendo escala micrométrica. Os esquemas foram obtidos com o auxílio de microscópio estereoscópico Zeiss, modelo Stemi SV6, equipada com câmara clara. Para exame ao microscópio eletrônico de varredura (MEV), fragmentos de folhas foram desidratados e submetidos à série etanólica ascendente. Em seguida, foram levados ao ponto crítico, utilizando-se o secador CPD-30, sendo, então, metalizados com ouro e levados ao MEV para observação e registro fotográfico.

Nas legendas das figuras são usadas as abreviaturas: ST (secção transversal); VF (vista frontal); MEV (microscopia eletrônica de varredura); MO (microscopia óptica).

\section{RESULTADOS}

\section{Morfologia}

A folha de E. brasiliensis é simples, elíptica-oboval, de margem inteira, semi-coriácea, com base simétrica e ápice agudo atenuado ou arredondado (Fig. 1). O limbo mede de 8 a $15 \mathrm{~cm}$ de comprimento por 4,5 a $6,5 \mathrm{~cm}$ de largura. O pecíolo mede de 6 a $10 \mathrm{~mm}$ de comprimento por 2 a $3 \mathrm{~mm}$ de diâmetro na base. As folhas provenientes da floresta, geralmente, apresentam maiores dimensões do que as da restinga. Em estado natural, a folha é verde nas duas faces, com tonalidade mais escura na superfície adaxial, a qual apresenta-se lisa e brilhante. Quando jovens, as folhas apresentam coloração vinácea, devido à presença de antocianina. $O$ padrão de venação é do tipo camptódromo-broquidódromo (Fig. 2). Comparando-se os esquemas das aréolas e das terminações de nervuras, de folhas provenientes da restinga e da floresta, constata-se maior densidade vascular nos indivíduos desenvolvidos na restinga (Fig.3).

\section{Descrição anatômica}

As características anatômicas gerais da lâmina foliar de E. brasiliensis revelam que a folha é hipostomática, glabra, dorsiventral, com tendência à isobilateralidade. A epiderme apresenta notável espessamento da cutícula e dos estratos cuticulares. No mesofilo, em posição subepidérmica, ocorrem numerosas cavidades secretoras de óleos essenciais, distribuídas pelas duas faces da lâmina foliar. Os cristais de oxalato de cálcio ocorrem na forma de drusas, dispersos no parênquima lacunoso.

\section{Sistema de revestimento}

A epiderme da face adaxial da folha de $E$. brasiliensis apresenta, em vista frontal, células de contorno sinuoso (Fig. 4). São visíveis, na periferia celular, regiões mais claras alternadas com outras mais escuras, o que reflete o espessamento desigual das paredes periclinais externas. Em MEV, este relevo não é visualizado devido ao grande espessamento da cutícula e dos estratos cuticulares. Em secção transversal, constatase que esse espessamento heterogêneo das paredes periclinais externas das células epidérmicas resulta na formação de pequenas projeções em direção ao lume celular (Fig. 5). Essas características também ocorrem nas células epidérmicas da face abaxial, porém de forma mais atenuada. As regiões da epiderme adaxial situadas sobre as cavidades secretoras de óleos essenciais são reconhecidas, em vista frontal, pela presença de uma célula central, de contorno circular (Fig.4), às vezes, poligonal, com dimensões um pouco menores do que as adjacentes e com menor afinidade tintorial (Fig.6). A superfície epidérmica, em MEV revela a ocorrência de estrias paralelas sobre a nervura mediana (Fig.7), enquanto no restante da lâmina foliar, o aspecto é homogêneo, não sendo possível a observação do contorno das células epidérmicas (Fig.8). Analisando-se secções transversais dessa face da lâmina foliar, verificase que a epiderme é uniestratificada e apresenta notável espessamento da cutícula, dos estratos cuticulares e das paredes periclinais externas (Fig.5). Esse espessamento chega a ultrapassar, ligeiramente, a altura das células epidérmicas. Sobre a nervura mediana e o bordo foliar, as células epidérmicas, de dimensões um pouco menores do que no restante da lâmina foliar, apresentam flanges cuticulares.

Os estômatos, do tipo anomocítico, encontramse limitados à superfície abaxial da folha e situam-se no mesmo nível das demais células epidérmicas. Nas folhas provenientes da restinga, a freqüência estomática é de 381 por $\mathrm{mm}^{2}$, enquanto nas folhas coletadas na floresta, a média encontrada é de 264 estômatos por $\mathrm{mm}^{2}$. Na Tabela 1 apresenta-se a comparação estatística da freqüência estomática dos indivíduos de $E$. brasiliensis dos dois ambientes. As células situadas sobre as estruturas secretoras são semelhantes às descritas na epiderme adaxial (Fig.9). Em MEV visualiza-se o contorno de algumas dessas células, além dos estômatos (Fig.10). Sobre a nervura mediana, a superfície abaxial mostra as estrias epicuticulares mais atenuadas, em relação às da superfície adaxial.

Nos testes histoquímicos, constatou-se a presença de compostos taníferos em todos os elementos epidérmicos das duas faces da lâmina foliar e, em muitas dessas células ocorrem, também, gotículas de lipídios. Observou-se, ainda, reação positiva ao teste de glicídios redutores e de compostos pécticos, excetuando-se, neste último teste, a cutícula e seus estratos. As folhas provenientes da restinga e da floresta assemelham-se, no que diz respeito às substâncias testadas, do ponto de vista qualitativo, porém diferenciam-se quanto à riqueza dos compostos encontrados, que é maior nos indivíduos 
provenientes da restinga.

Lâmina foliar: a secção transversal da lâmina foliar, em sua região mediana, apresenta estrutura dorsiventral, com tendência à isobilateralidade (Fig.11a,b). O parênquima paliçádico é constituído por um único estrato celular, apresentando, intercaladas, cavidades secretoras adjacentes à epiderme. Estas apresentam secção circular ou piriforme, com dimensões que ultrapassam a altura do parênquima paliçádico (Fig.11a,b), conectando-se com o estrato epidérmico através de uma ou duas células tabulares, de conteúdo denso. Essas cavidades secretoras também ocorrem na face abaxial do mesofilo. Seu epitélio secretor é constituído por células de secção elíptica e paredes delgadas, apresentando-se totalmente comprimidas nas estruturas mais desenvolvidas. O conteúdo dessas estruturas secretoras é quimicamente complexo, tendo reagido positivamente aos testes de lipídios, glicídios redutores e taninos. Em secções paradérmicas observamse essas estruturas secretoras não seccionadas, as quais revelam-se globosas e com dimensões variáveis (Fig.12). Comparando-se, estatisticamente, os indivíduos provenientes da restinga e da floresta, constata-se que, no primeiro ambiente, ocorre maior produção de estruturas secretoras de óleos essenciais nas duas faces da lâmina foliar (Tab. 2). O parênquima lacunoso apresenta cerca de 9 estratos celulares, em folhas provenientes da floresta, enquanto nas da restinga, esse número varia de 12 a 13. Idioblastos contendo drusas de oxalato de cálcio ocorrem no mesofilo (Fig.11b). Esses cristais são mais numerosos nos indivíduos oriundos da floresta. A conexão entre o parênquima paliçádico e o lacunoso é feita por meio de células coletoras (Fig.13), as quais se conectam com um número variável de células do parênquima paliçádico. Os feixes vasculares menos desenvolvidos são do tipo colateral e os de maior porte são do tipo bicolateral, ambos guarnecidos com fibras lignificadas. Os testes histoquímicos revelaram a presença de compostos taníferos, em grande quantidade, em todo o mesofilo. Glicídios redutores foram detectados em algumas células do parênquima lacunoso e gotículas de lipídios ocorrem dispersas por todo o parênquima. $\mathrm{Na}$ Tabela 3 encontram-se listadas as principais diferenças anatômicas entre as folhas de E. brasiliensis coletadas nas áreas de restinga e de floresta.

$O$ bordo foliar: apresenta-se levemente fletido em direção à face abaxial (Fig.14), com as características anatômicas e histoquímicas semelhantes às descritas para o restante da lâmina foliar. O parênquima paliçádico estende-se até a proximidade da região distal do bordo, porém com células menos altas. Os elementos epidérmicos dessa região também são menores e apresentam flanges cuticulares (Fig.14). Em sua região distal, o bordo é constituído por colênquima, o qual encontra-se mais desenvolvido nos exemplares provenientes da restinga, comparativamente aos coletados na floresta. No parênquima lacunoso ocorre um feixe vascular colateral e uma ou duas cavidades secretoras sub-epidérmicas

Nervura mediana: Em secção transversal, a nervura mediana apresenta-se côncava na região ventral e convexa na dorsal (Fig.15a,b). A epiderme apresenta as células menores do que no restante da lâmina foliar, com as demais características semelhantes às já descritas, não se observando, entretanto, estômatos. Constata-se, ainda, nesta região, a ocorrência de flanges cuticulares. O parênquima paliçádico é substituído, na porção central da nervura mediana, por 3 a 4 estratos de colênquima, do tipo anelar. Internamente ao colênquima, ocorrem de 12 a 16 estratos de células parenquimáticas, as quais delimitam espaços intercelulares de pequenas dimensões. Algumas drusas de oxalato de cálcio ocorrem neste tecido. A seguir, em posição mediana, encontra-se o sistema vascular rodeado por fibras esclerenquimáticas (Fig.16). O xilema localiza-se centralmente, e, em suas regiões ventral e dorsal, encontra-se o floema, envolvendo-o quase continuamente. $\mathrm{O}$ conjunto assume a forma de um arco, com a abertura voltada para a face adaxial (Fig.16). Na região dorsal da nervura ocorrem cerca de 12 estratos de células parenquimáticas semelhantes às que ocorrem na região ventral.

Pecíolo: A região mediana do pecíolo, em secção transversal, apresenta a superfície adaxial ligeiramente côncava e a abaxial, convexa (Fig.17a,b).

A epiderme é uniestratificada, com células de paredes espessadas e sem estômatos.

A cutícula e os estratos cuticulares apresentamse muito espessados e insinuam-se entre as paredes anticlinais das células epidérmicas, formando flanges.

Na região cortical encontra-se um parênquima colenquimatoso (Fig. 18), com cerca de 20 a 26 estratos celulares, observando-se cloroplastos nos mais periféricos. Várias drusas de oxalato de cálcio ocorrem no córtex do pecíolo. Comparando-se as amostras coletadas na restinga e na floresta, constatou-se maior quantidade de cristais nos exemplares provenientes deste último ambiente.

As cavidades secretoras ocorrem em toda a periferia do pecíolo e são semelhantes às da lâmina foliar (Figs.18 e 19).

Na região central do pecíolo situa-se o sistema vascular, em forma de um arco, constituído por xilema e floema que o envolve totalmente(Fig.17 a, b). Ao redor do floema ocorrem fibras não lignificadas.

Os testes histoquímicos revelaram a presença de lipídios, em grande quantidade, nas estruturas secretoras, nas células da epiderme e do parênquima. Em torno do sistema vascular ocorre uma bainha amilífera. Compostos taníferos são encontrados em todo o pecíolo. Foi positivo, ainda, o teste para glicídios redutores, nas células parenquimáticas adjacentes ao sistema vascular, nas estruturas secretoras, nas fibras, no parênquima xilemático e no floema. A comparação dos testes histoquímicos nos pecíolos de plantas provenientes da

Rev. Bras. Farmacogn. Braz J. Pharmacogn 17(3): Jul./Set. 2007 
restinga e da floresta, revela, à semelhança do que se constatou na análise da lâmina foliar, que os indivíduos da restinga apresentam maior concentração de compostos ergásticos.

\section{DISCUSSÃO}

A avaliação morfológica e anatômica das folhas de Eugenia brasiliensis revelou a presença de características universais da família Myrtaceae, bem como características distintivas, importantes para orientar a diagnose da espécie em questão. Entre as primeiras, Solereder (1908) e Metcalfe; Chalk (1950), destacam a ocorrência de cavidades secretoras, a presença de floema interno ao xilema, abundância notável de tanino, oxalato de cálcio na forma de cristais solitários ou agrupados, estômatos anomocíticos ou paracíticos. Todas essas características foram constatadas no material botânico examinado. Cronquist (1981) menciona que as folhas das Myrtaceae apresentam uma nervura intramarginal contínua, o que foi confirmado na espécie aqui estudada.

Barroso; Peron (1994) chamam a atenção para o habitus das espécies de Myrtaceae, como uma característica pouco explorada, mencionando a ocorrência de espécimes de Myrcia pubipetala, Calyptranthes concinna e Eugenia cuprea, com alturas variando de 2 até 26 metros de altura. Segundo esses autores, o porte mais alto deve representar o habitus real de uma espécie plenamente desenvolvida e os de menor altura são indivíduos em desenvolvimento, precocemente floridos e frutificados. No presente estudo, constatou-se que E. brasiliensis apresenta portes diferentes, segundo o ambiente em que se desenvolve. $\mathrm{Na}$ restinga, onde os exemplares encontram-se expostos à intensa luminosidade, todos os indivíduos observados apresentam porte arbustivo, enquanto na floresta, onde essa espécie recebe menor incidência de luz, a altura dos espécimes observados corresponde à de pequenas árvores.

A análise das características anatômicas da folha de E. brasiliensis é apresentada a seguir, discutindose as peculiaridades da espécie, relacionadas ao sistema de revestimento, mesofilo e sistema vascular.

Considerando-se o sistema de revestimento da folha de E. brasiliensis, chama a atenção o notável espessamento da cutícula e dos estratos cuticulares da epiderme, especialmente nos indivíduos proveniente da restinga. Este revestimento revelou-se, ainda, rico em substâncias hidrófobas, evidenciando a sua funcionalidade como mecanismo protetor contra a perda excessiva de água através da superfície foliar.

Barthlot (1981) refere que o contorno das paredes e a escultura da superfície celular da epiderme são características importantes, podendo ter valor taxonômico. No presente estudo verificou-se que as células epidérmicas das folhas de E. brasiliensis apresentam as paredes anticlinais sinuosas, sendo esta característica mais acentuada na face adaxial, diferenciando-se, assim, do que ocorre, segundo Napp-Zinn (1973), na maioria dos casos. A análise da epiderme, tanto em microscopia óptica (M.O.), como em microscopia eletrônica de varredura (M.E.V.), revelou que a superfície cuticular de E. brasiliensis é lisa, sem ornamentações.

Com relação às projeções parietais encontradas nas células epidérmicas de $E$. brasiliensis, encontrou-se, na literatura, que outras plantas apresentam estruturas semelhantes. Morretes (1967) registrou a presença de desigualdades na espessura das paredes periclinais e anticlinais das células epidérmicas de Anacardium nanum St. Hil. (Anacardiaceae). Na família Myrtaceae, essa característica é observada apenas nas paredes periclinais externas e encontra-se registrada na descrição anatômica de Eugenia sulcata Spring. Ex Mart. (Machado et al., 1988), em duas espécies de Gomidesia (Gomes, 1992), em Psidium cattleyanum Sabine (Arruda; Fontenelle, 1994) e em diversas espécies de Eugenia (Fontenelle et al., 1994). Barros (1998) encontrou estruturas semelhantes em Plinia martinelli G. Barroso \& Peron e Callado (1993/1997), em Eugenia cuprea e Marlieria suaveolens. Naturalmente, essas projeções parietais ampliam a superfície protoplasmática das células epidérmicas. É digno de nota que as cavidades secretoras das Myrtaceae têm origem na epiderme, onde, de uma única inicial, forma-se um grupo de células, às quais são acrescidas outras, originadas no estrato subepidérmico (Carr; Carr, 1970; Barros, 1998). Se o aumento da superfície da membrana plasmática pode ser associado ao transporte, à absorção ou à secreção de solutos, poderíamos supor que essas células epidérmicas com projeções em suas paredes, também estejam envolvidas com tais funções. Para elucidar esta questão, entretanto, torna-se necessário a realização dos devidos experimentos fisiológicos.

Entre as características anatômicas das células epidérmicas que recobrem as cavidades secretoras, destaca-se a menor espessura da parede externa da célula de topo, constituindo um indício de que o material produzido por estas estruturas deva ser liberado para o meio, através dessa parede. Tunmanm (1909) afirma que as células de cobertura das estruturas secretoras de Eugenia apiculata são revestidas por uma cutícula muito delgada. List et al. (1995), ao analisarem as glândulas oleíferas de Melaleuca alternifolia (Myrtaceae), verificaram que elas são recobertas por células epidérmicas modificadas. Ao observar folhas submetidas ao vácuo, esses autores constatam que o óleo atravessa as células de cobertura, depositando-se na superfície foliar, em forma de gotículas. Eles sugerem, então, que em condições naturais, no campo, também deva ocorrer a liberação desse óleo, das glândulas para o meio, de modo semelhante ao observado experimentalmente, porém de forma mais gradativa e atenuada. 
Napp-Zinn (1984) refere que a densidade estomática de representantes do gênero Eugenia diminui de acordo com o aumento da umidade relativa. Comparando-se o número médio de estômatos por $\mathrm{mm}^{2}$ em E. brasiliensis coletada na restinga e na floresta, constata-se a veracidade da afirmativa daquele autor, visto que, no primeiro ambiente, a média de estômatos equivale a $380 / \mathrm{mm}^{2}$ e, no segundo, a $263 / \mathrm{mm}^{2}$. Weaver; Clements (1929) atribuem à limitação do crescimento das células epidérmicas o aumento do número de estômatos por unidade de área, o que está de acordo com as menores dimensões verificadas nas lâminas foliares de E. brasiliensis da restinga, comparadas com as da floresta. Larcher (2000) lembra que, apenas por pouco tempo, os estômatos permanecem totalmente abertos, pois, raramente, todas as condições favoráveis à sua abertura ocorrem ao mesmo tempo. Dessa forma, continua Larcher (l.c.) não é de se estranhar que, justamente nas folhas mais sujeitas a stress hídrico apresentem a freqüência média de estômatos superior à de folhas mais protegidas da radiação solar.

Uma das características marcantes do mesofilo das Myrtaceae é a ocorrência de cavidades secretoras subepidérmicas, distribuídas pelas duas faces da lâmina foliar. O seu conteúdo é típico para cada espécie, sendo formado por substâncias lipídicas voláteis, denominadas, genericamente, de óleos essenciais. Os seus componentes químicos apresentam particularidades importantes para a farmacologia, devido aos efeitos fisiológicos que provocam. São importantes, também, para a produção de essências, utilizadas na indústria de alimentos, perfumaria e cosméticos. Siani et al. (1998) analisaram os óleos essenciais de 12 espécies de Myrtaceae, revelando a presença de substâncias terpenóides. Esses mesmos autores encontraram, nos extratos aquosos das folhas dessas plantas, substâncias glicosídicas e fenólicas, o que está de acordo com os dados obtidos no presente trabalho. Eschrich (1995) afirma que os óleos voláteis, geralmente, são mono e sesquiterpenos. Fahn (1979) afirma que as cavidades secretoras podem secretar apenas terpenos ou terpenos junto com carbohidratos e outras substâncias. Castro; Machado (2003) referemse à mistura de óleos essenciais e compostos fenólicos encontrados em cavidades secretoras de algumas espécies, como sendo uma secreção heterogênea, de natureza lipofílica. Ainda segundo essas autoras, os óleos voláteis podem atrair agentes polinizadores ou, às vezes, repelir insetos, reduzindo a herbivoria. A atmosfera de todo o mundo recebe, segundo estimativas citadas por Went (1974), em cada ano, aproximadamente 1,4 milhões de toneladas de óleos essenciais.

Meyer; Canny (1975) correlacionaram a precipitação pluviométrica com o conteúdo oleífero das folhas de Eucalyptus, em diferentes locais da Austrália, constatando que quanto maior a precipitação média anual, menor é o número de glândulas por $\mathrm{cm}^{2}$ e menor a porcentagem de óleo no volume foliar. No presente estudo, foi possível constatar a veracidade dessa afirmativa, pois os indivíduos de E. brasiliensis desenvolvidos no ambiente de restinga apresentam maior quantidade de estruturas secretoras de óleos essenciais em suas folhas, em comparação com os indivíduos da floresta.

As folhas de E. brasiliensis exibem características consideradas indicadoras de xeromorfismo, tais como o notável espessamento da cutícula e dos estratos cuticulares, o mesofilo com tendência à organização isobilateral, independentemente do ambiente de origem, ressaltando-se, entretanto, que na restinga, essas características são mais acentuadas. Outro indício de xeromorfismo, segundo Eschrich (1995), é a intensa vascularização nas folhas que se desenvolvem em ambientes secos, pois, além de servir para o transporte, o sistema vascular auxilia na sustentação do mesofilo. Essa afirmativa está de acordo com os dados obtidos no presente estudo, onde a comparação de folhas diafanizadas, coletadas na restinga e na floresta, permitiu a constatação que a densidade vascular das folhas oriundas da restinga é maior.

\section{AGRADECIMENTOS}

Ao Departamento de Botânica do Instituto de Biologia da USP pela utilização do microscópio eletrônico de varredura e suporte laboratorial.

Tabela 1. Densidade de estômatos ocorrentes em área foliar equivalente a $0,053 \mathrm{~mm}^{2}$ (área do campo do microscópio) na superfície abaxial de Eugenia brasiliensis. Com o nível de significância igual a 5\%, o teste $t$ revela que o número de estômatos nas folhas da restinga é maior do que o das folhas da floresta.

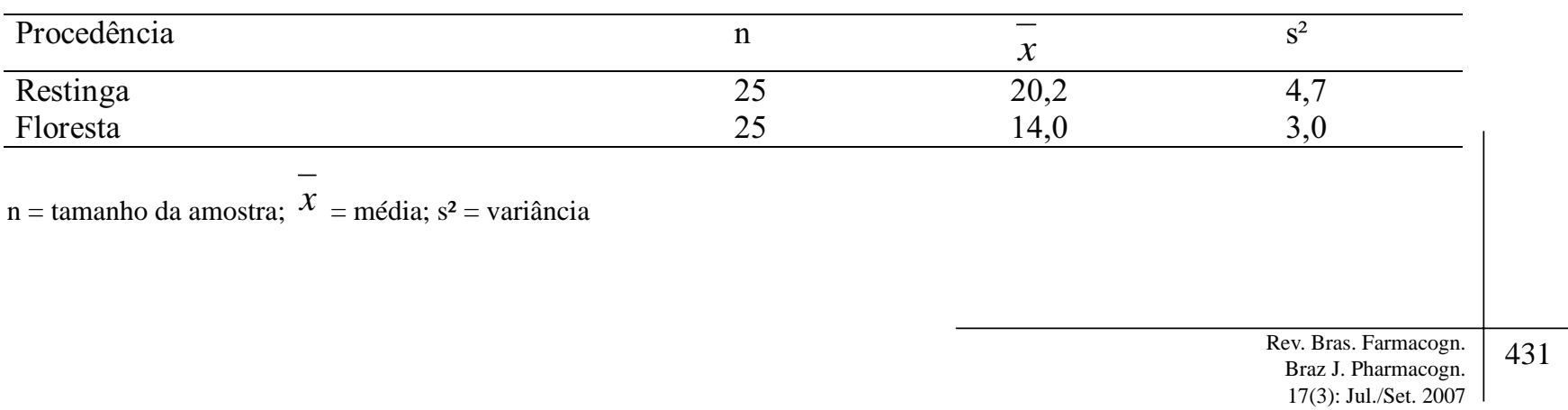


Tabela 2. Densidade de cavidades secretoras em área foliar equivalente a 0,053 $\mathrm{mm}^{2}$ (área do campo do microscópio) na lâmina foliar de Eugenia brasiliensis. Com o nível de significância de 5\%, o teste $t$ revela que as folhas coletadas na restinga apresentam maior quantidade de cavidades secretoras de óleos essenciais em relação com as originárias da floresta.

\begin{tabular}{llll}
\hline Procedência/face da folha & $\mathrm{n}$ & $\bar{x}$ & $\mathrm{~s}^{2}$ \\
\hline Restinga/face adaxial & 25 & 2,5 & 0,56 \\
Restinga/face abaxial & 25 & 2,44 & 0,42 \\
Floresta/face adaxial & 25 & 1,5 & 0,25 \\
Floresta/face abaxial & 25 & 1,42 & 0,29 \\
\hline
\end{tabular}

$\mathrm{n}=$ tamanho da amostra; $\bar{X}=$ média; $\mathrm{s}^{2}=$ variância

Tabela 3. Principais diferenças anatômicas entre as folhas de Eugenia brasiliensis coletadas em restinga e floresta.

\begin{tabular}{lll}
\hline & Restinga & Floresta \\
\hline Densidade de estômatos & $381 / \mathrm{mm}^{2}$ & $264 / \mathrm{mm}^{2}$ \\
Espessura da lâmina foliar & $350 \mu \mathrm{m}$ & $310 \mu \mathrm{m}$ \\
Espessamento das paredes celulares & maior & menor \\
Concentração de compostos ergásticos & maior & menor \\
Quantidade de cristais & menor & maior \\
Cavidades secretoras/face adaxial & $47 / \mathrm{mm}^{2}$ & $28 / \mathrm{mm}^{2}$ \\
Cavidades secretoras/face abaxial & $46 / \mathrm{mm}^{2}$ & $27 / \mathrm{mm}^{2}$ \\
Altura das células do parênquima paliçádico & $56 \mu \mathrm{m}$ & $43 \mu \mathrm{m}$ \\
Número de estratos do parênquima lacunoso & 13 & 9 \\
Grau de lignificação e de anisotropia das paredes celulares & maior & menor \\
Densidade vascular & maior & menor \\
\hline
\end{tabular}

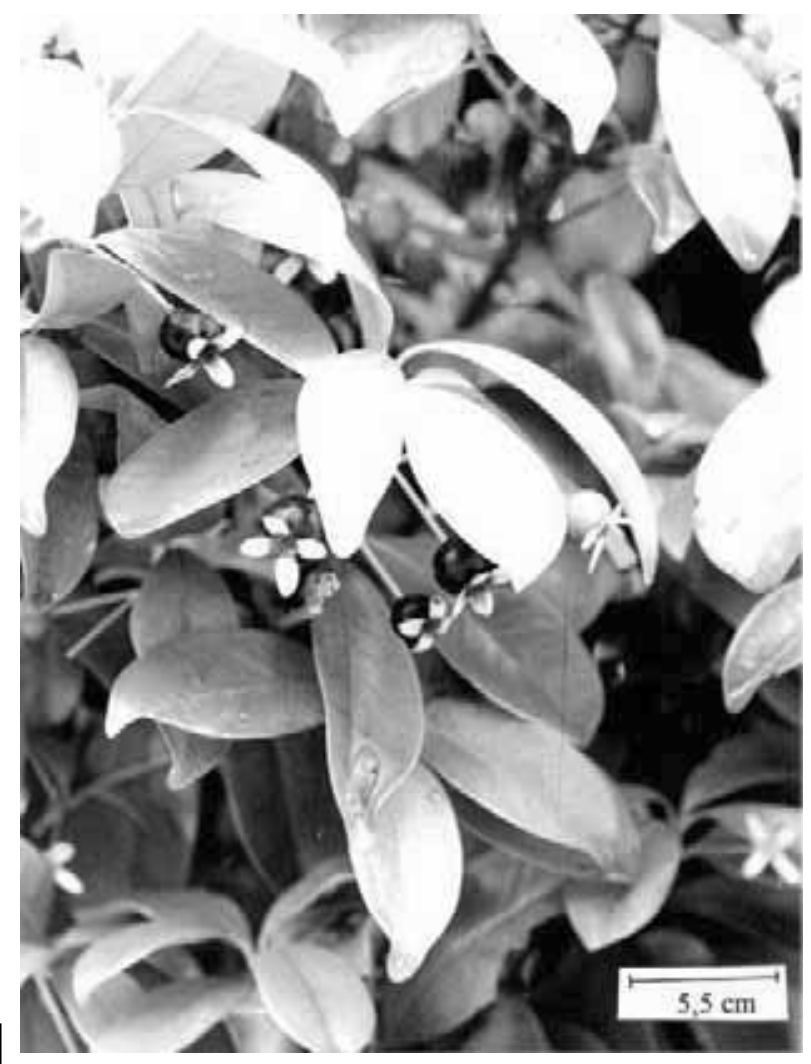

Figura 1. Eugenia brasiliensis (restinga) com Frutos $(05 / 11 / 2002)$.

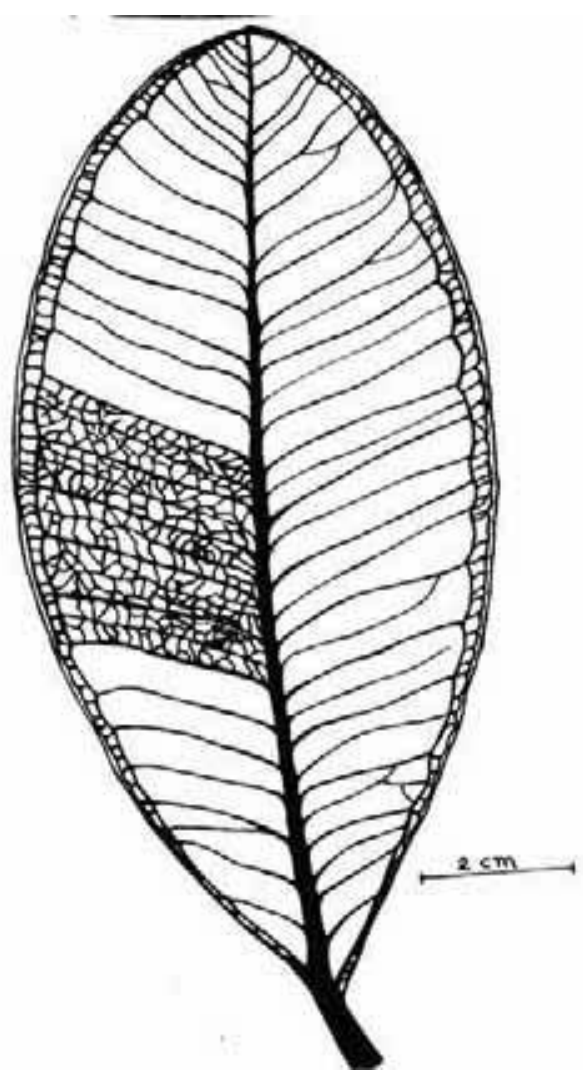

Figura 2. Folha de Eugenia brasiliensis (floresta), evidenciando o padrão de venação camptódromobroquidódromo. 

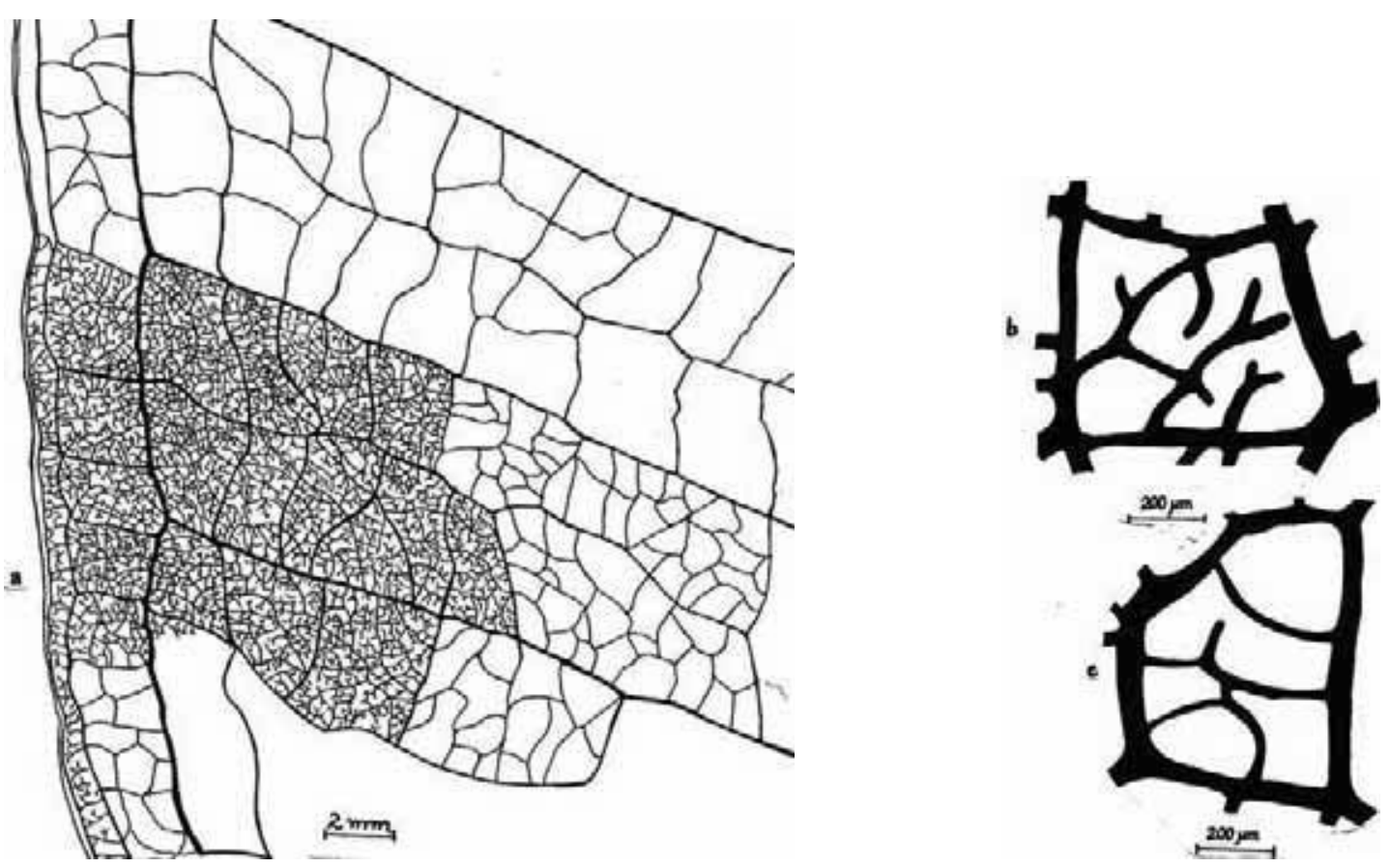

Figura 3. a) Pormenor da margem foliar de Eugenia brasiliensis (floresta); b) aréola e terminações de nervuras (restinga); c) aréola e terminações de nervuras (floresta).

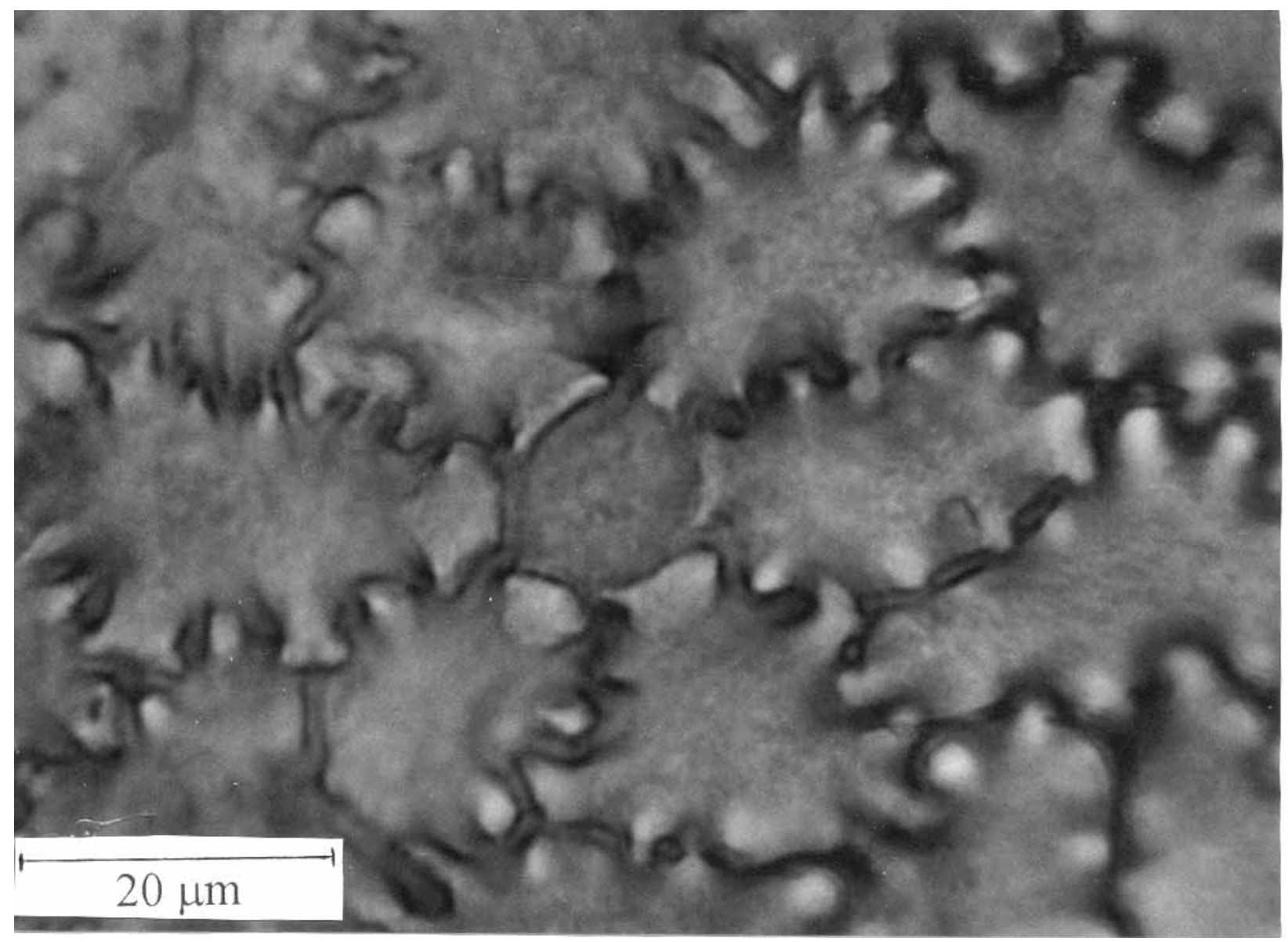

Figura 4. Eugenia brasiliensis (restinga). Pormenor da VF das células epidérmicas da face adaxial, na região da estrutura secretora. As regiões mais claras da periferia das células correspondem às porções mais delgadas das paredes periclinais externas. 


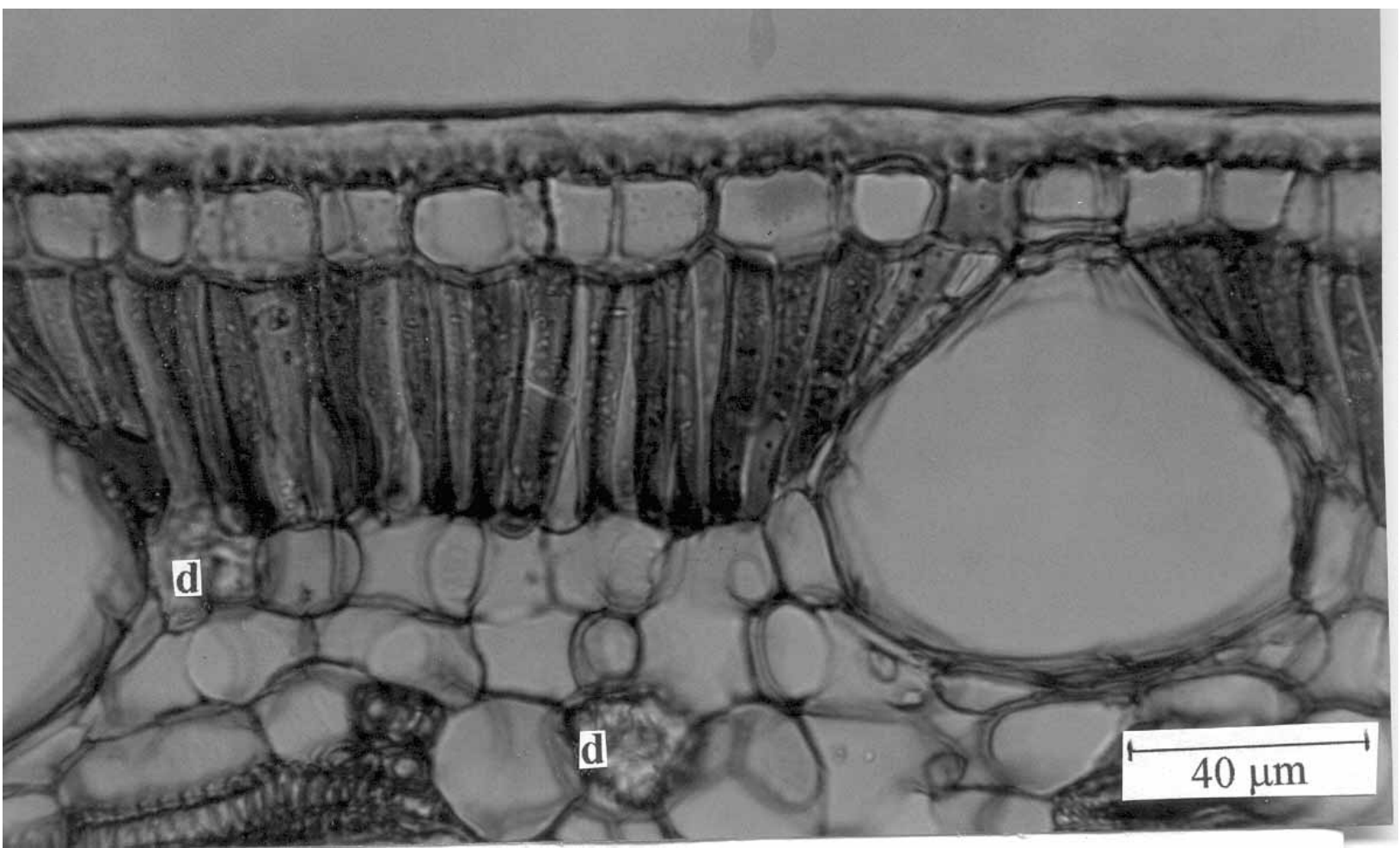

Figura 5. Eugenia brasiliensis (floresta). ST da região adaxial da lâmina foliar, evidenciando a epiderme, com suas projeções parietais e espesso revestimento. Destaca-se, ainda, uma estrutura secretora subepidérmica e drusas (d).

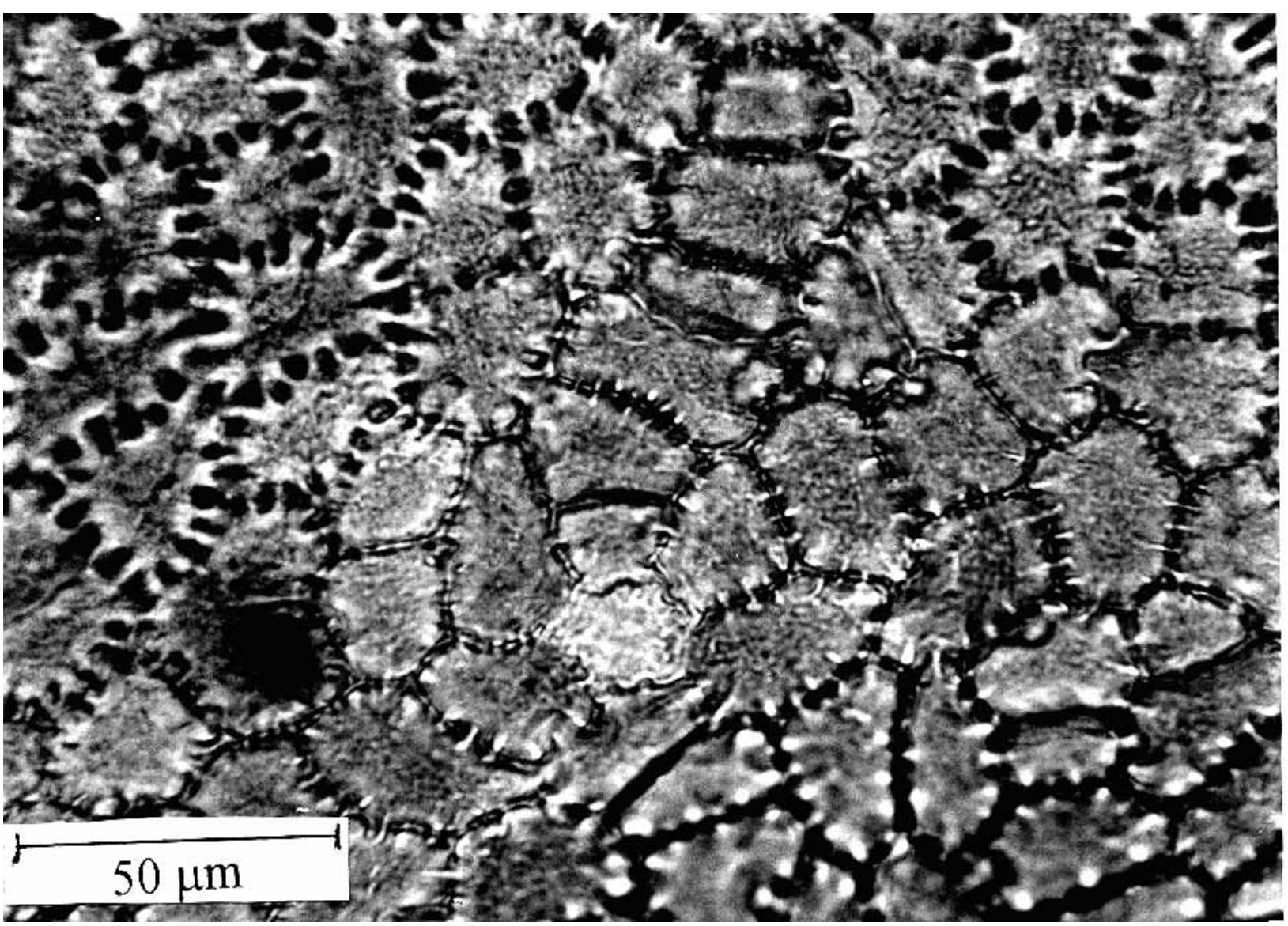

Figura 6. VF da epiderme da face adaxial de Eugenia brasiliensis (floresta), evidenciando a região sobre a estrutura secretora, cuja célula central apresenta-se mais clara. 


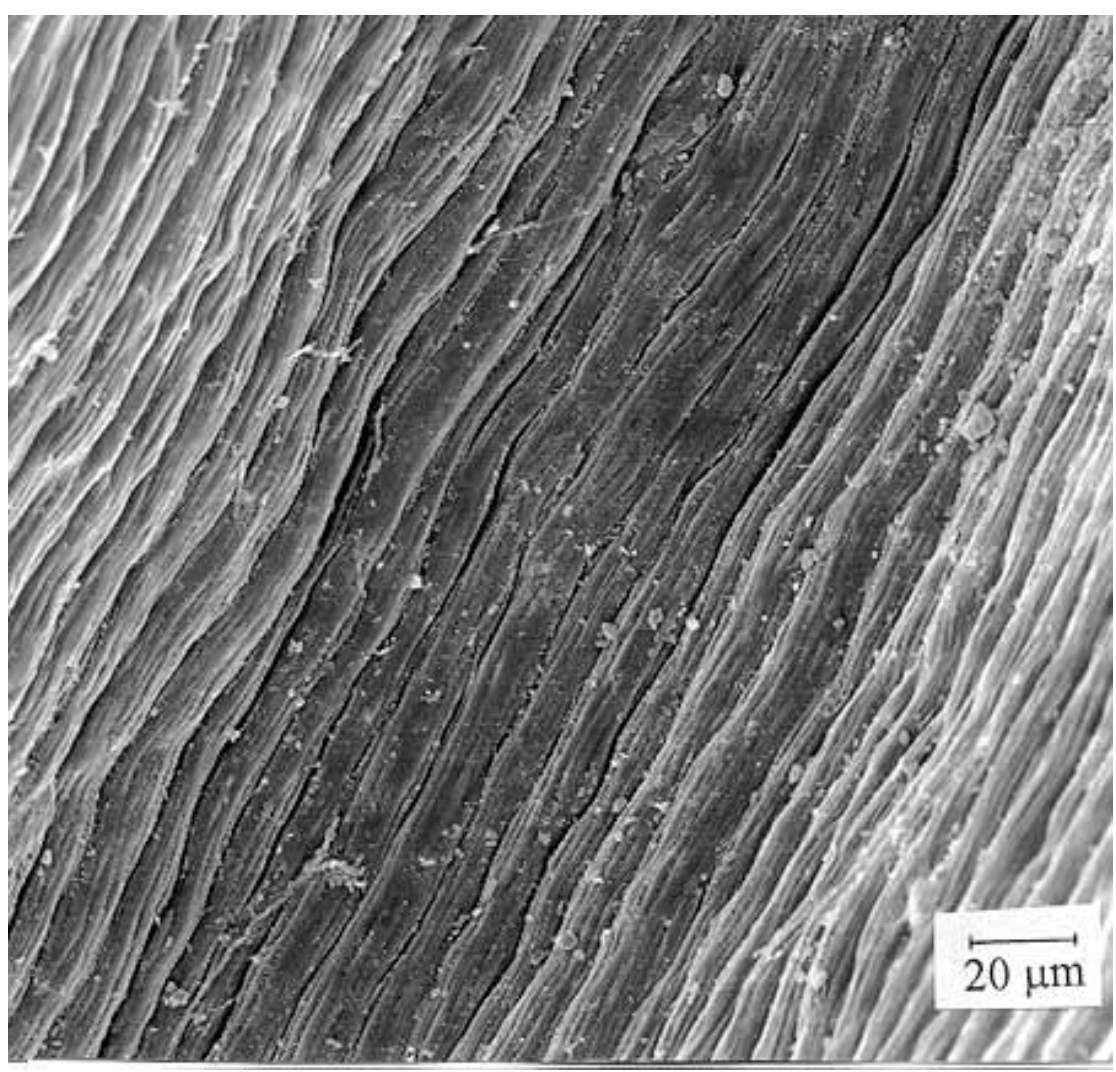

Figura 7. Eugenia brasiliensis (floresta). MEV. Epiderme da face abaxial, na região da nervura mediana, sendo visíveis as estrias epicuticulares.

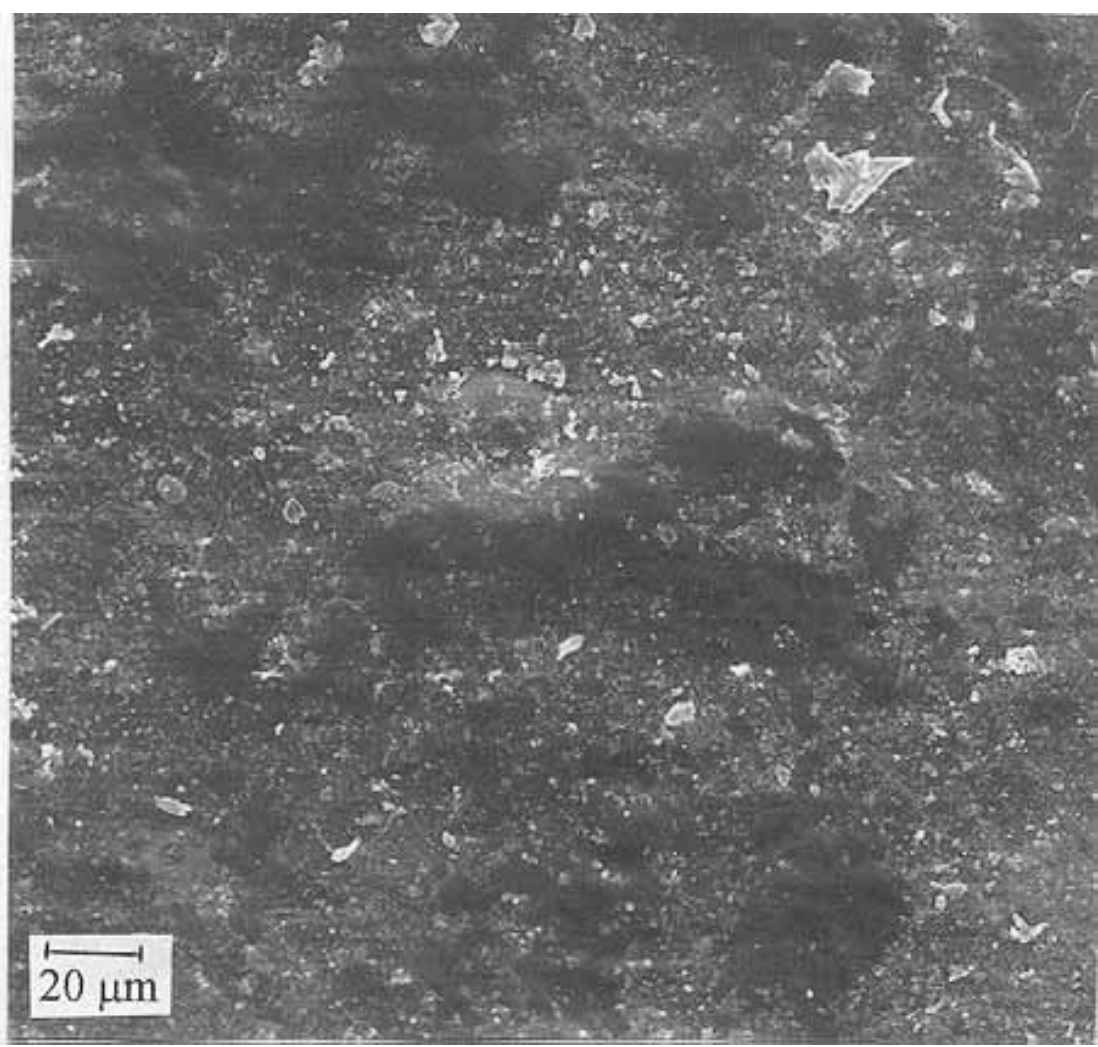

Figura 8. Eugenia brasiliensis (floresta). MEV. Epiderme da face adaxial na região intercostal. 


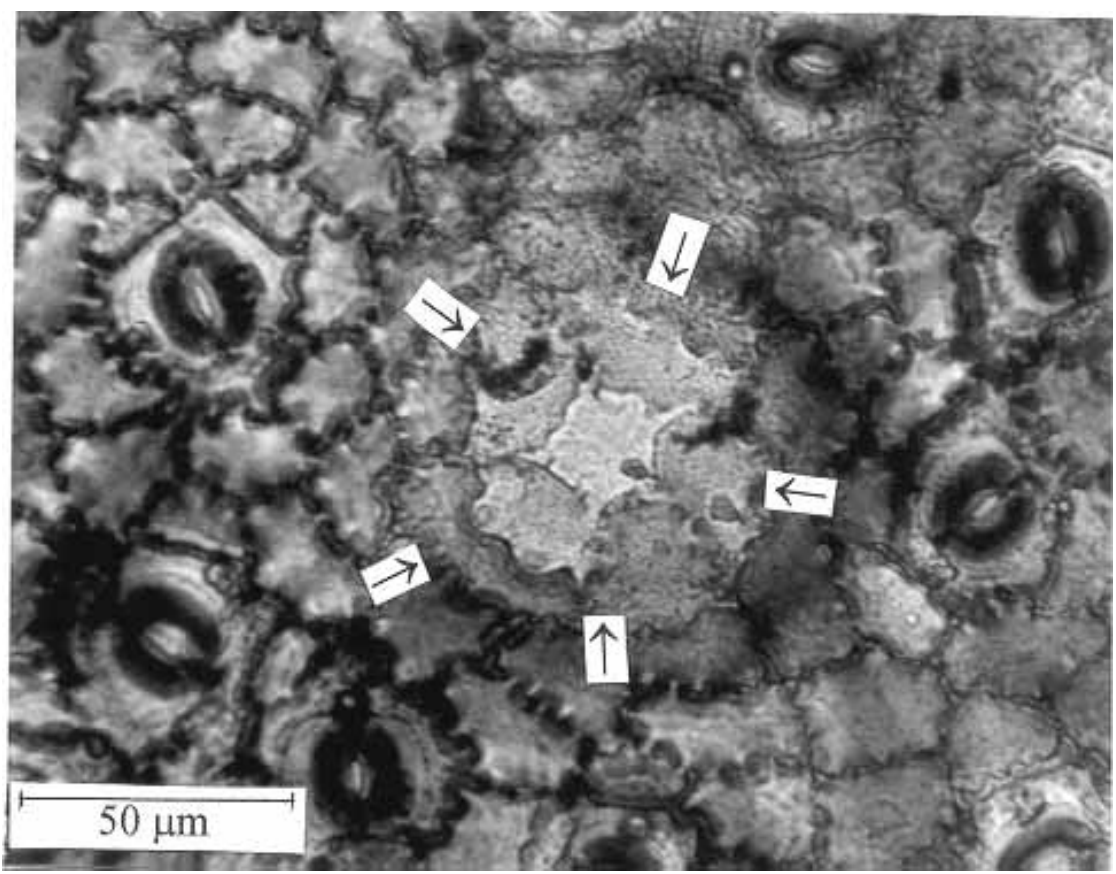

Figura 9. Eugenia brasiliensis (floresta). VF da epiderme da face abaxial, evidenciando os estômatos e a região que recobre a estrutura secretora, com a célula central apresentando contorno pentagonal.

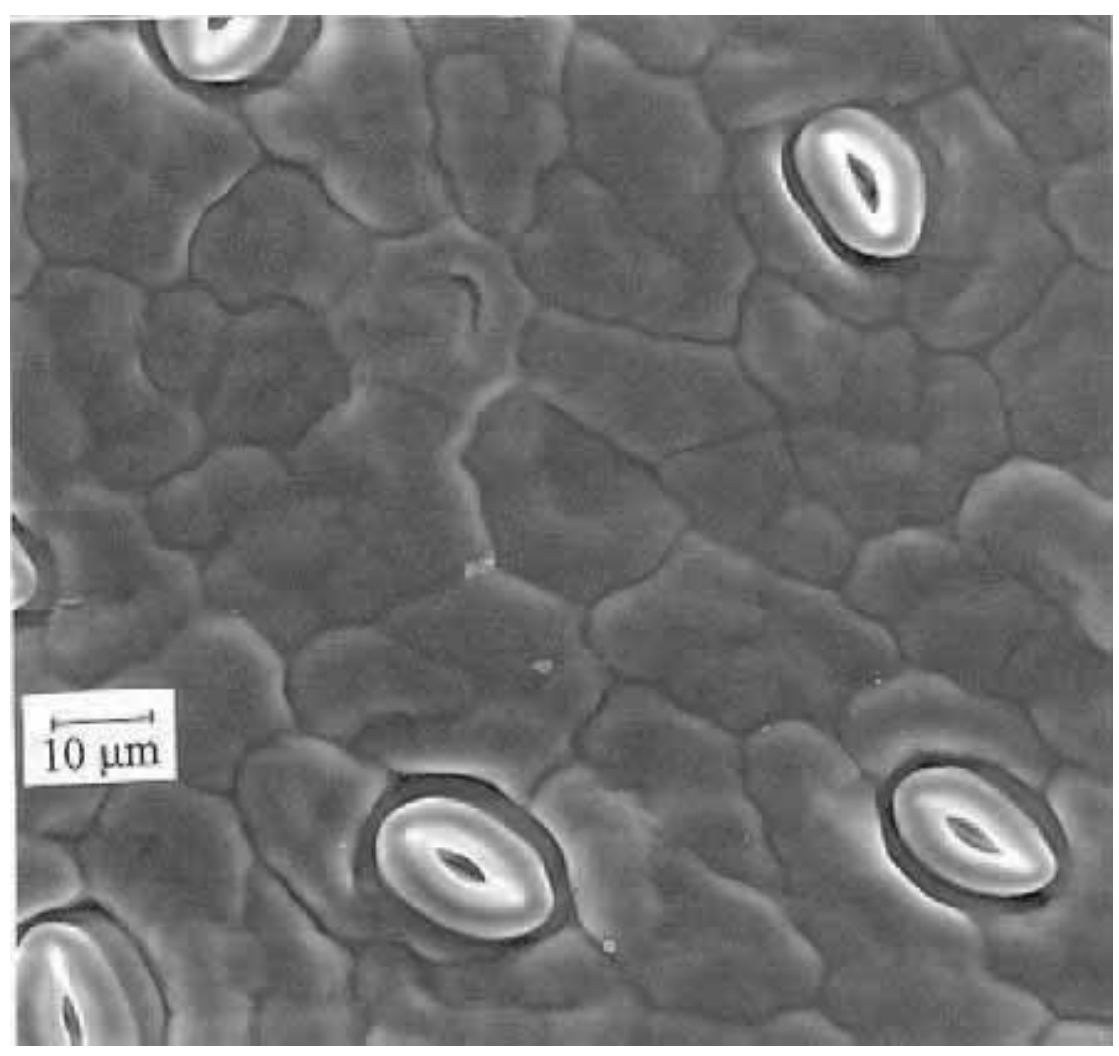

Figura 10. Eugenia brasiliensis (restinga). MEV. Epiderme da face abaxial, evidenciando os estômatos e, ao centro, as células que recobrem a estrutura secretora. 


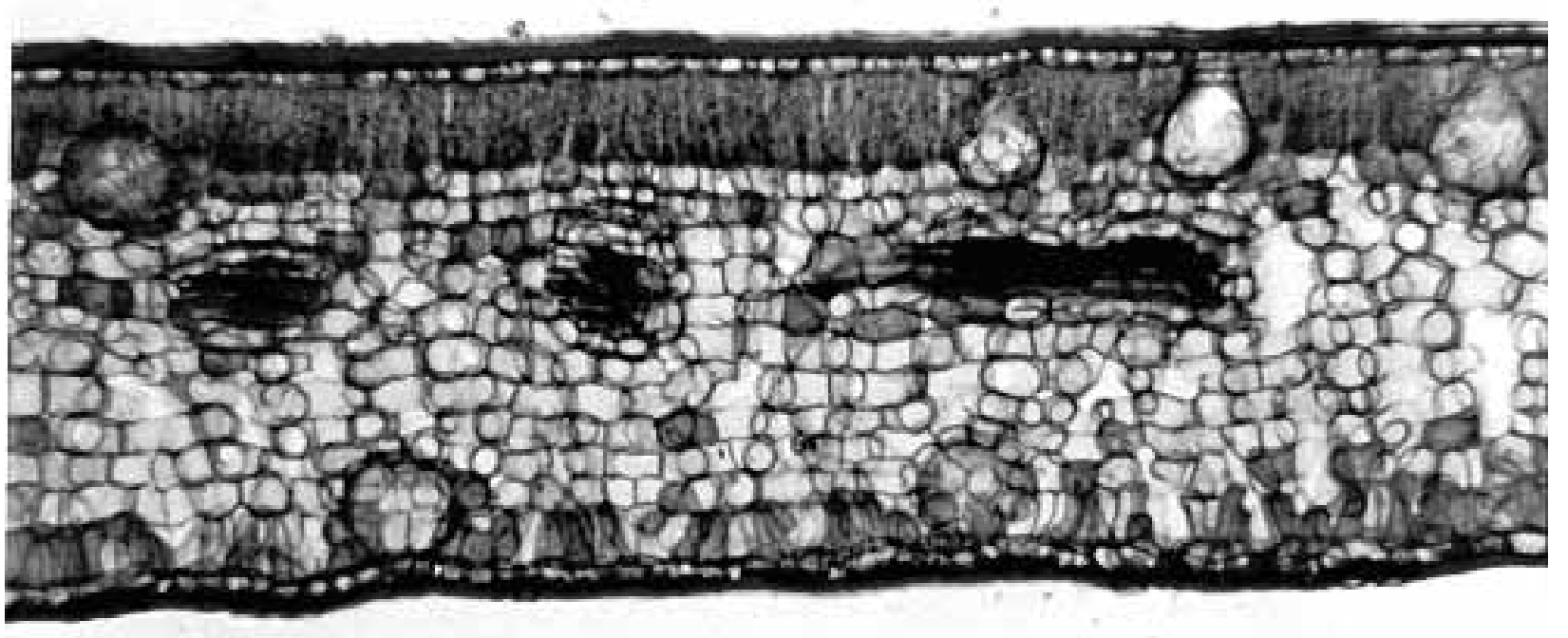

$\longmapsto 140 \mu \mathrm{m}$

Figura 11a. Eugenia brasiliensis (restinga). ST da lâmina foliar.

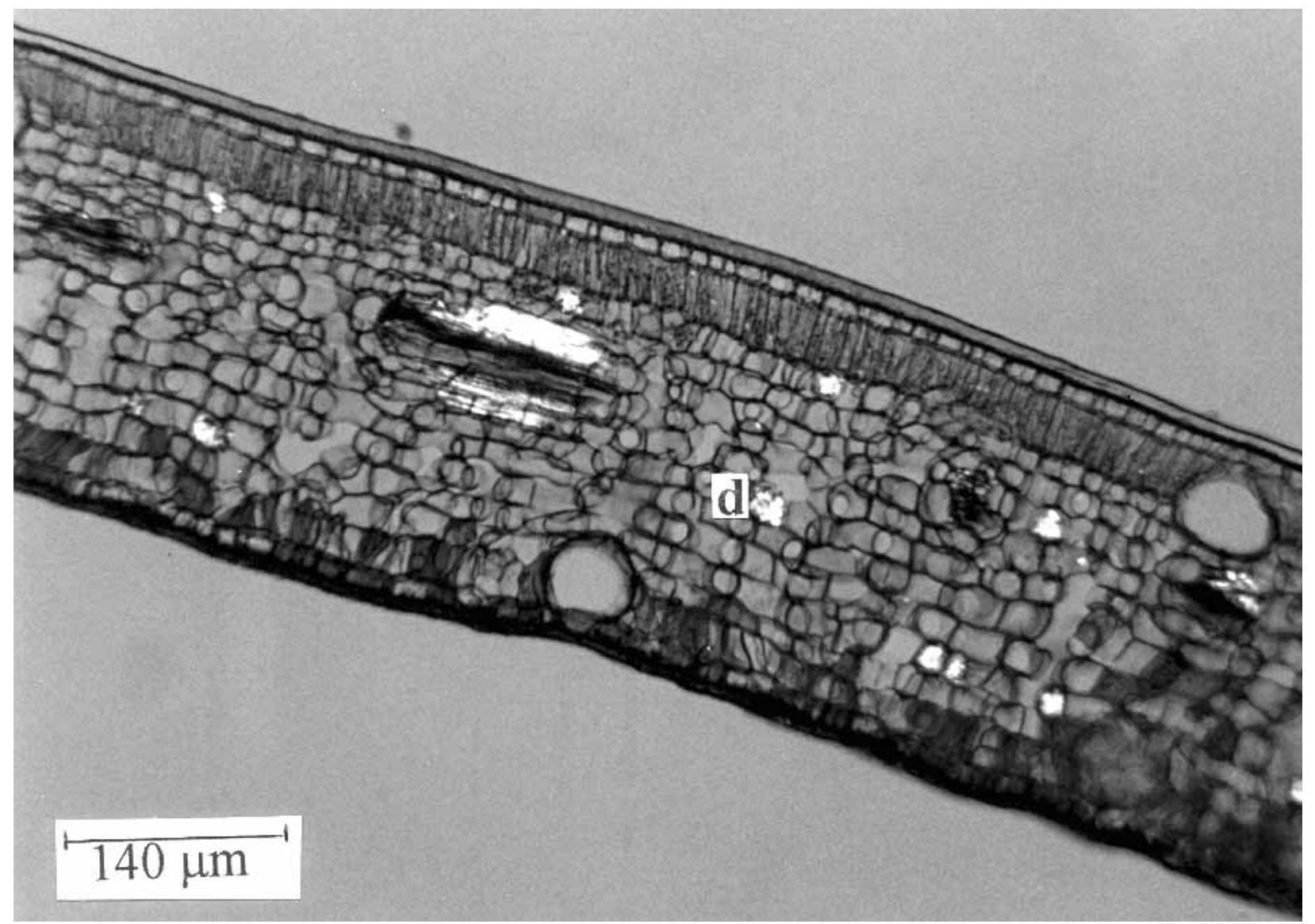

Figura 11b. Eugenia brasiliensis (floresta). ST da lâmina foliar, em luz polarizada (d = drusas). 


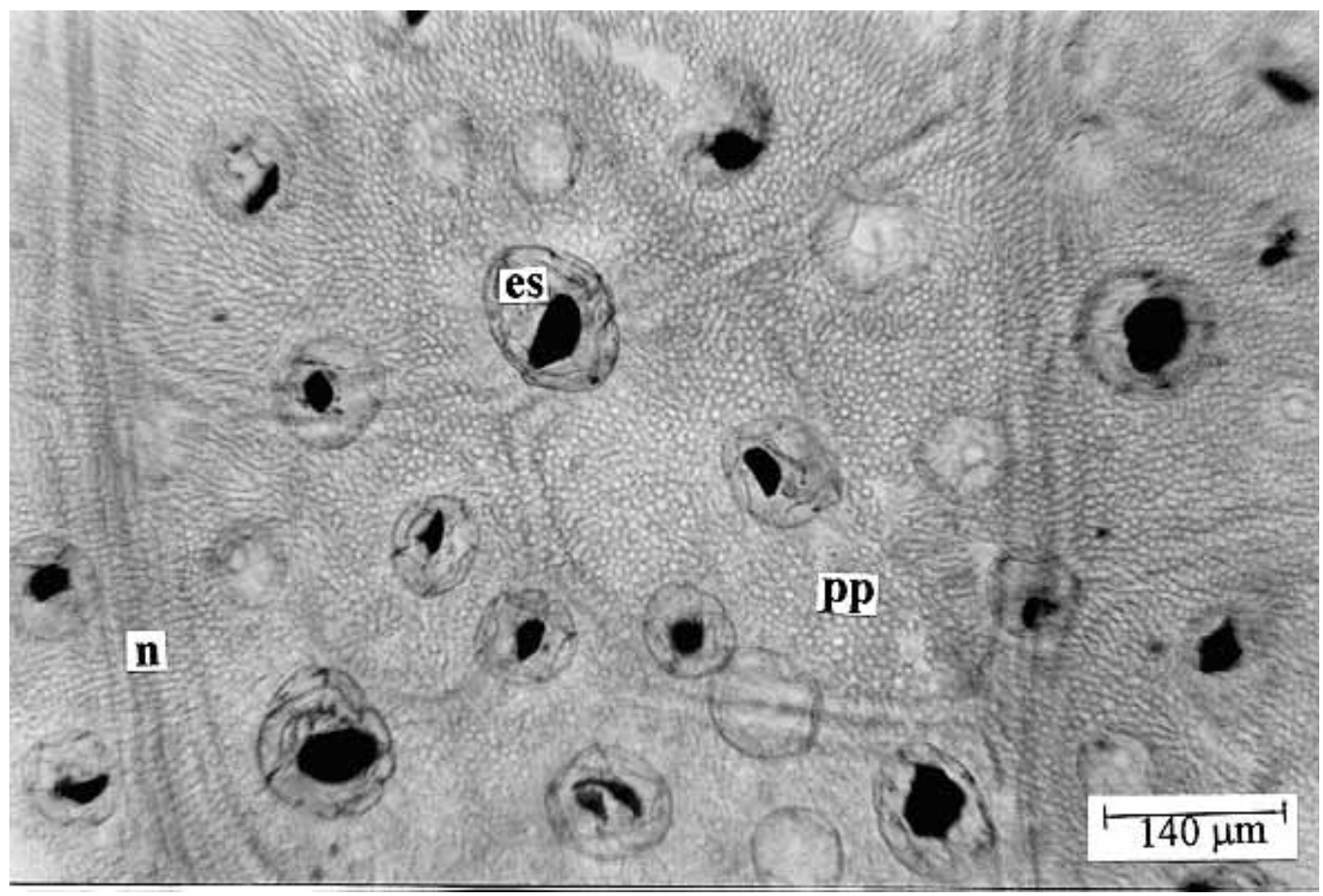

Figura 12. Eugenia brasiliensis (restinga). Secção paradérmica da lâmina foliar, evidenciando as estruturas secretoras (es), a nervação (n) e o parênquima paliçádico (pp).

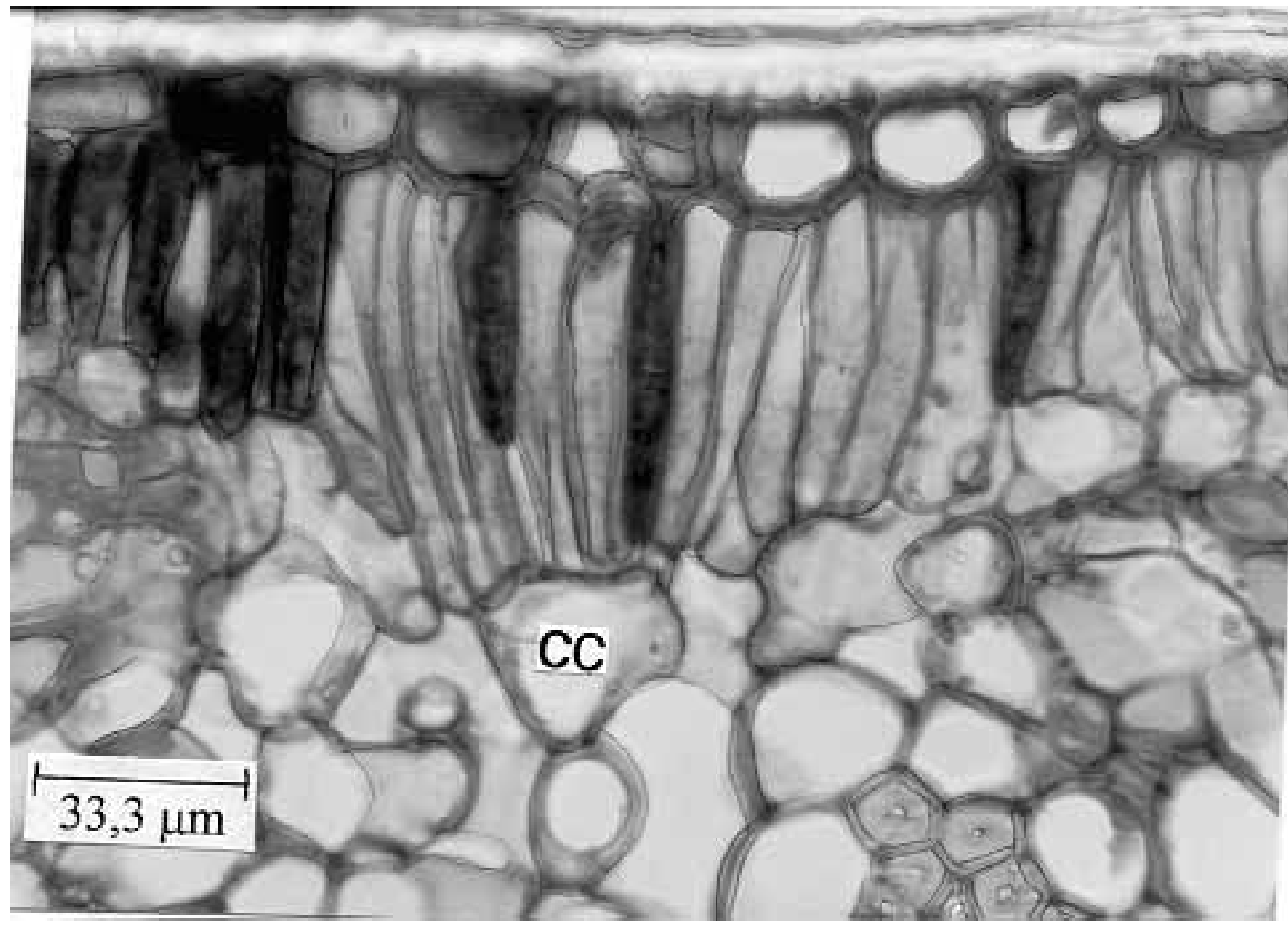

Figura 13. Eugenia brasiliensis (restinga). Pormenor da ST da lâmina foliar, evidenciando células coletoras (cc) entre o parênquima paliçádico e o lacunoso. 


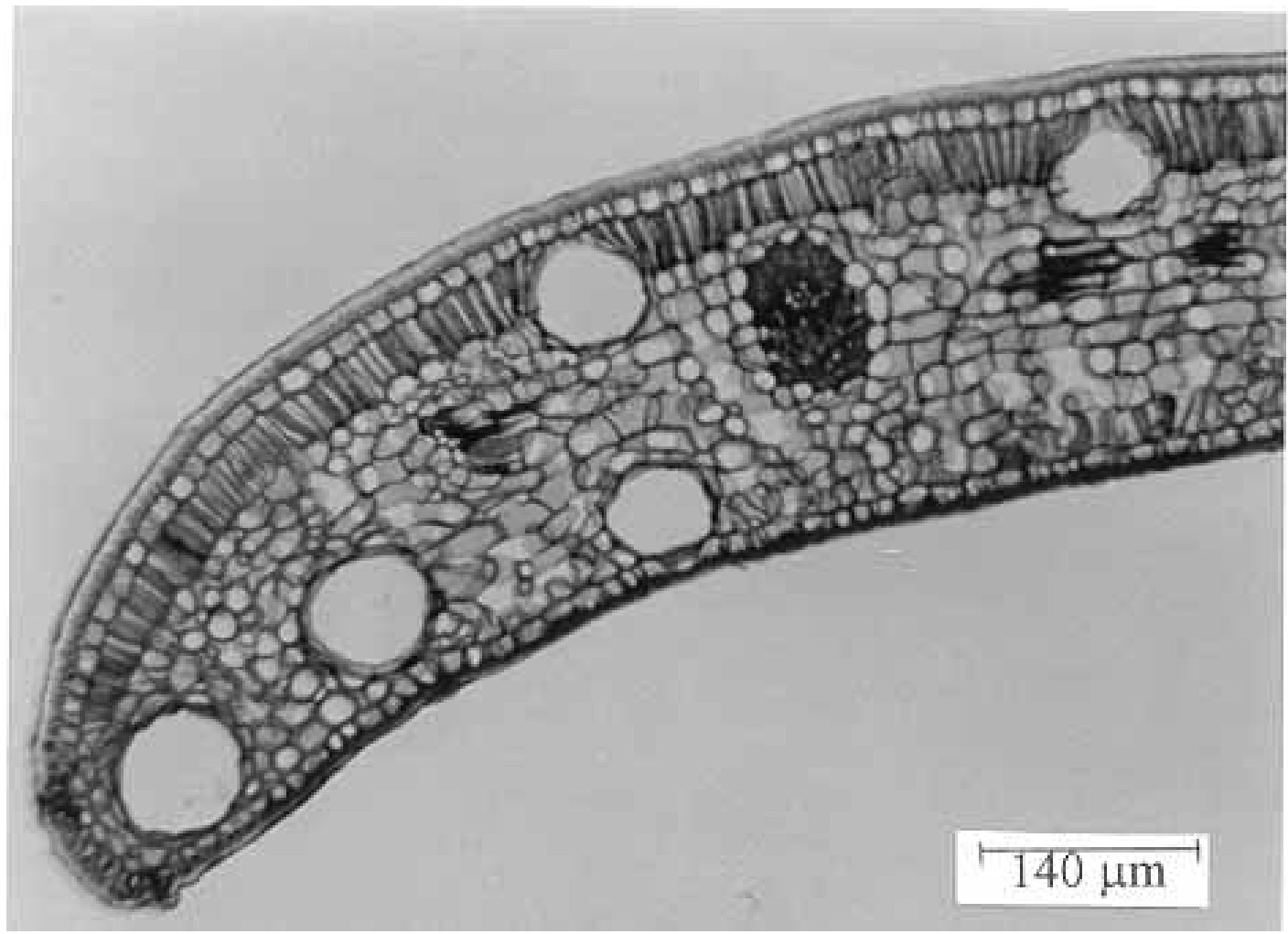

Figura 14. Eugenia brasiliensis (floresta). ST da lâmina foliar na região do bordo.

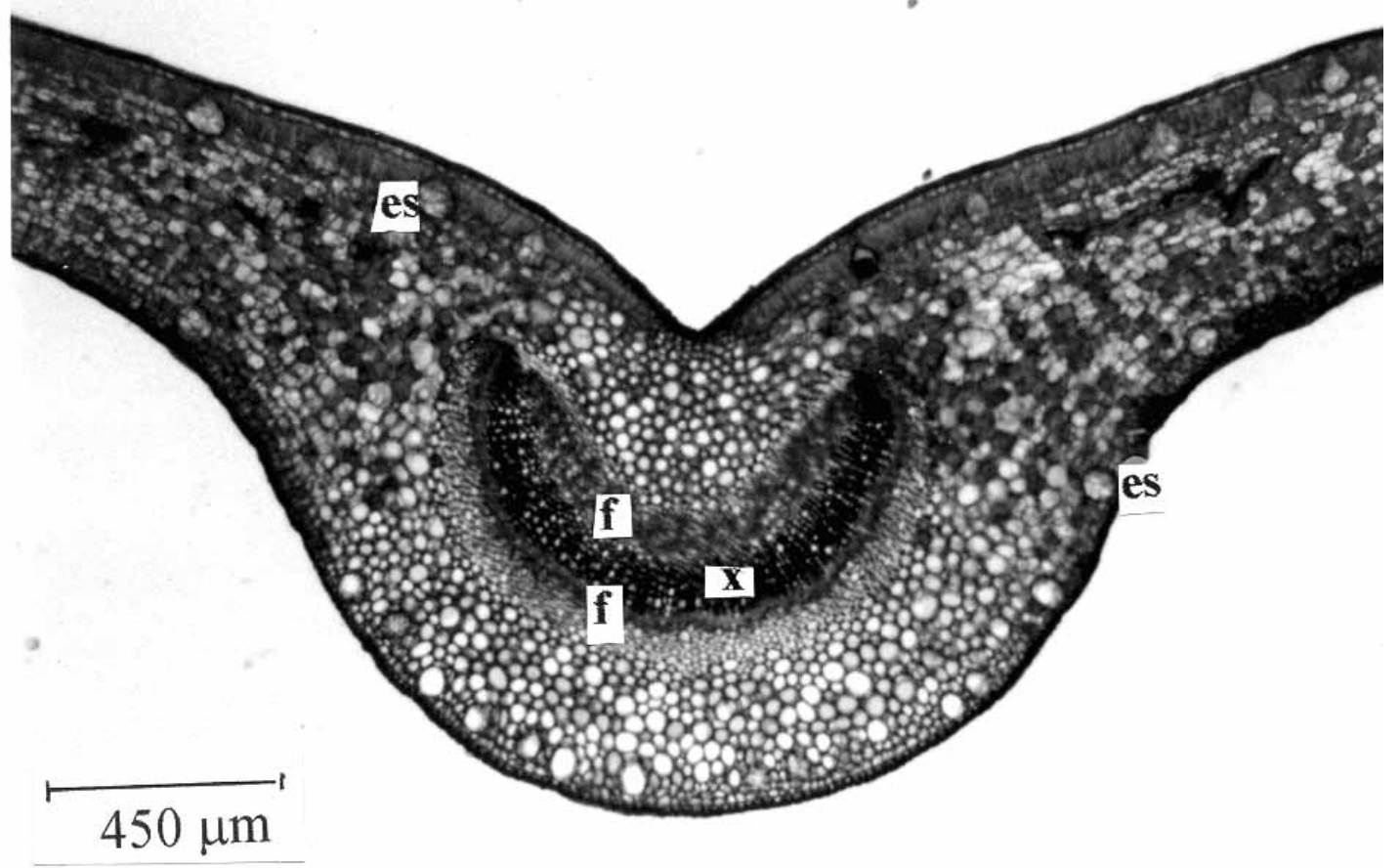

Figura 15a. Eugenia brasiliensis (restinga). ST da nervura mediana. $\mathrm{f}=$ floema; $\mathrm{x}=$ xilema; es $=$ estrutura secretora. 


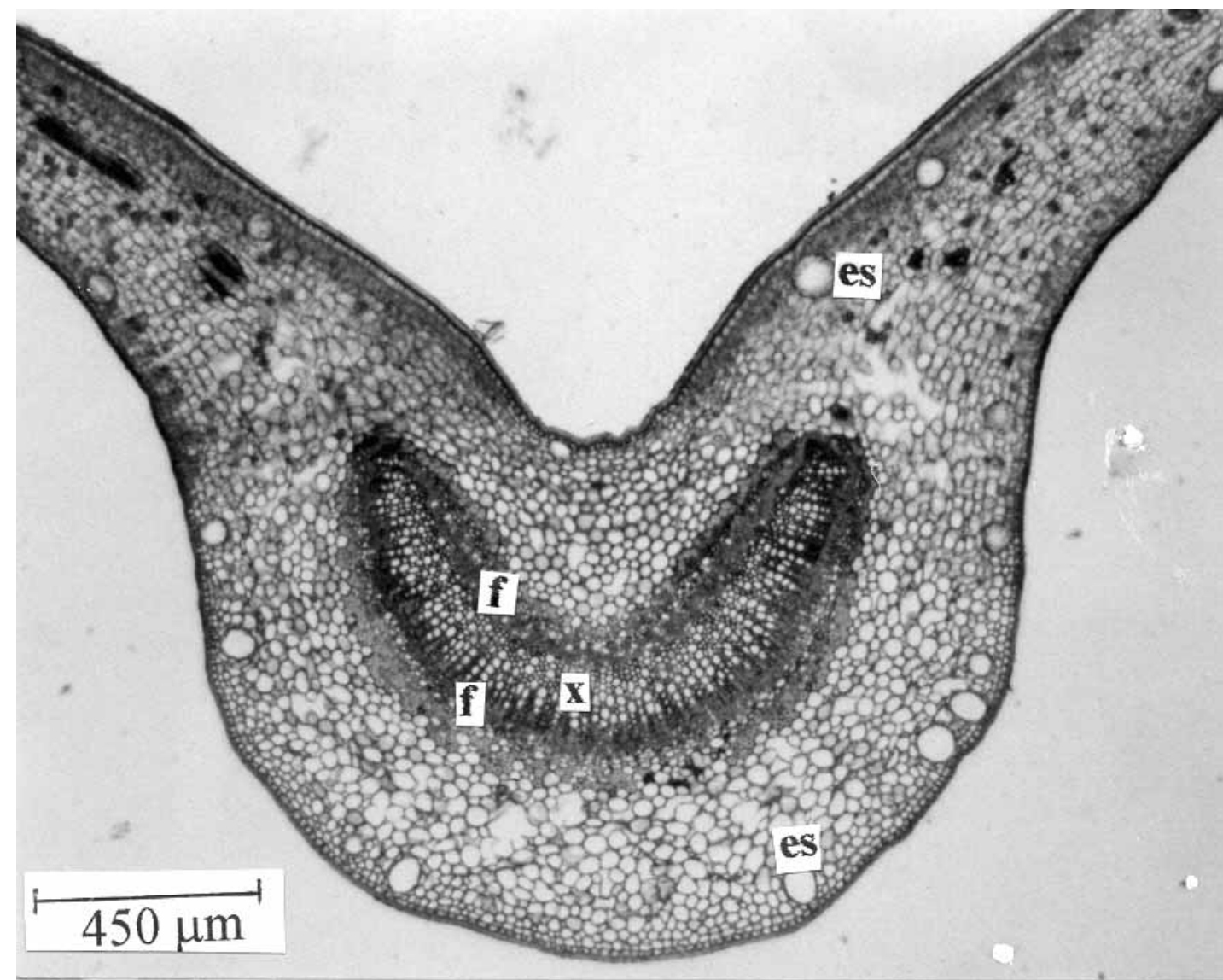

Figura 15b. Eugenia brasiliensis (floresta). ST da nervura mediana. $\mathrm{f}=$ floema; $\mathrm{x}=$ xilema; es $=$ estrutura secretora.

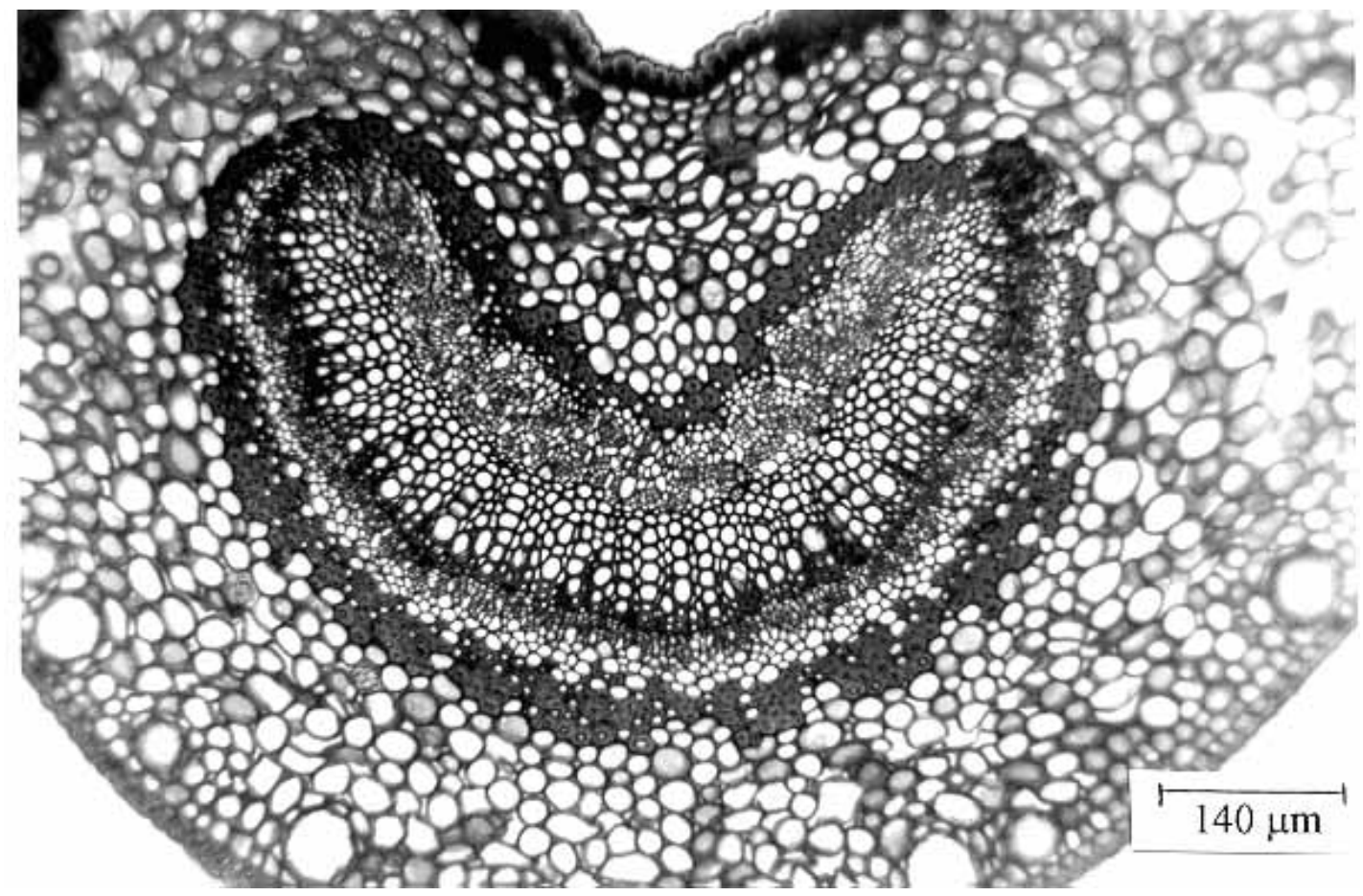

Figura 16. Eugenia brasiliensis (restinga). ST da nervura mediana, evidenciando o sistema vascular. 


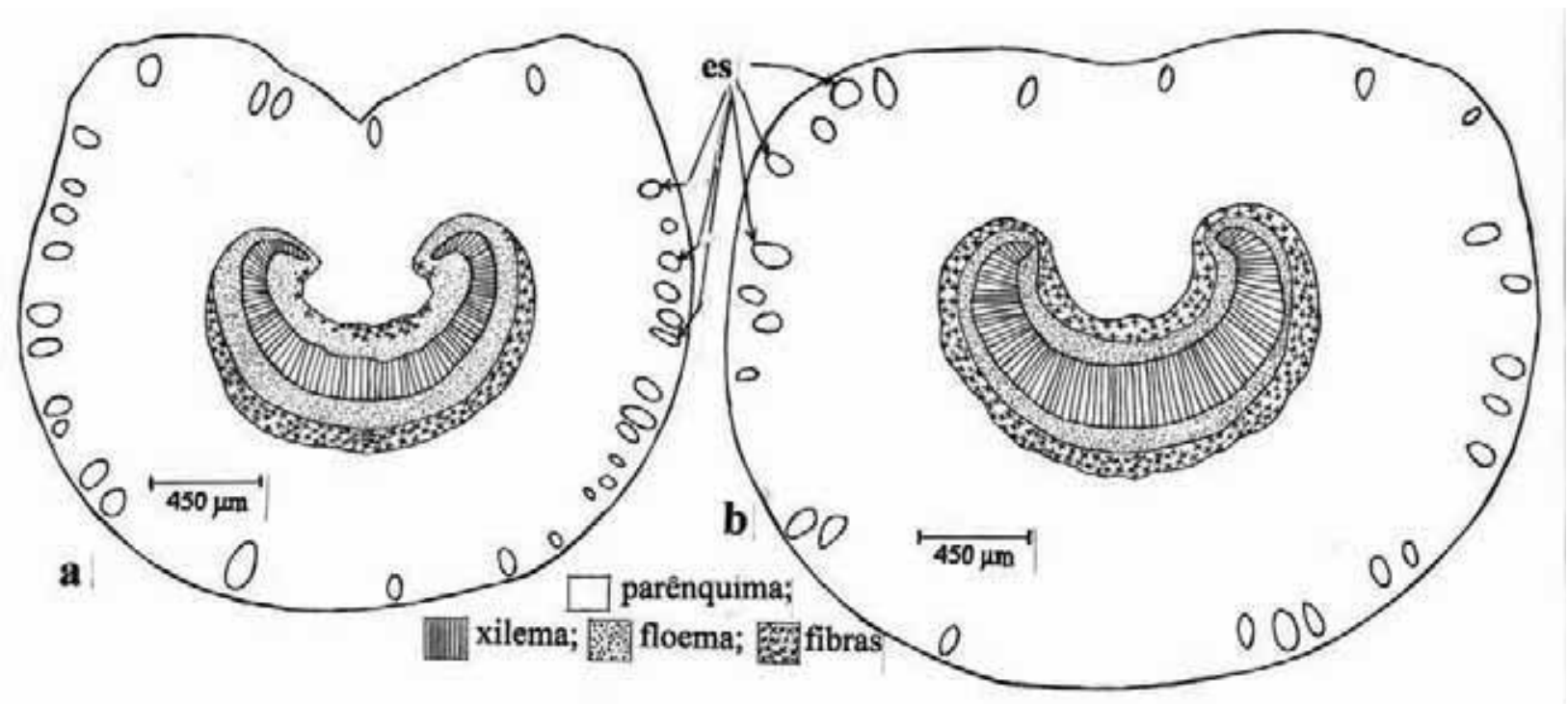

Figura 17. Esquemas da ST do pecíolo de Eugenia brasiliensis. a) proveniente da restinga; b) proveniente da floresta; es = estruturas secretoras.

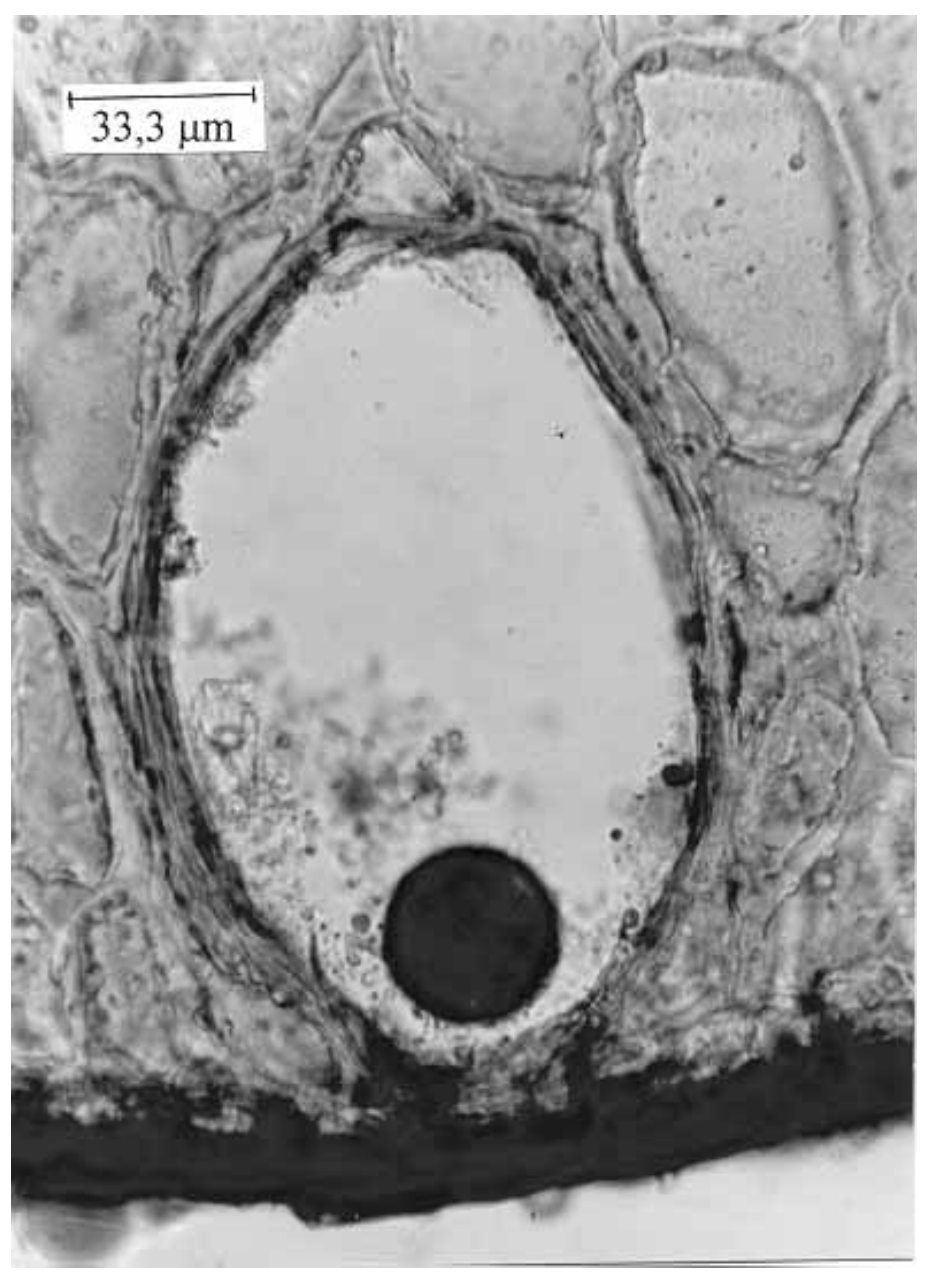

Figura 18. ST da região mediana do pecíolo de Eugenia brasiliensis (restinga), destacando-se uma estrutura secretora, cujo conteúdo reage positivamente ao teste de lipídios. Note-se, ainda, o grande espessamento das paredes das células parenquimáticas (parênquima colenquimatoso). 


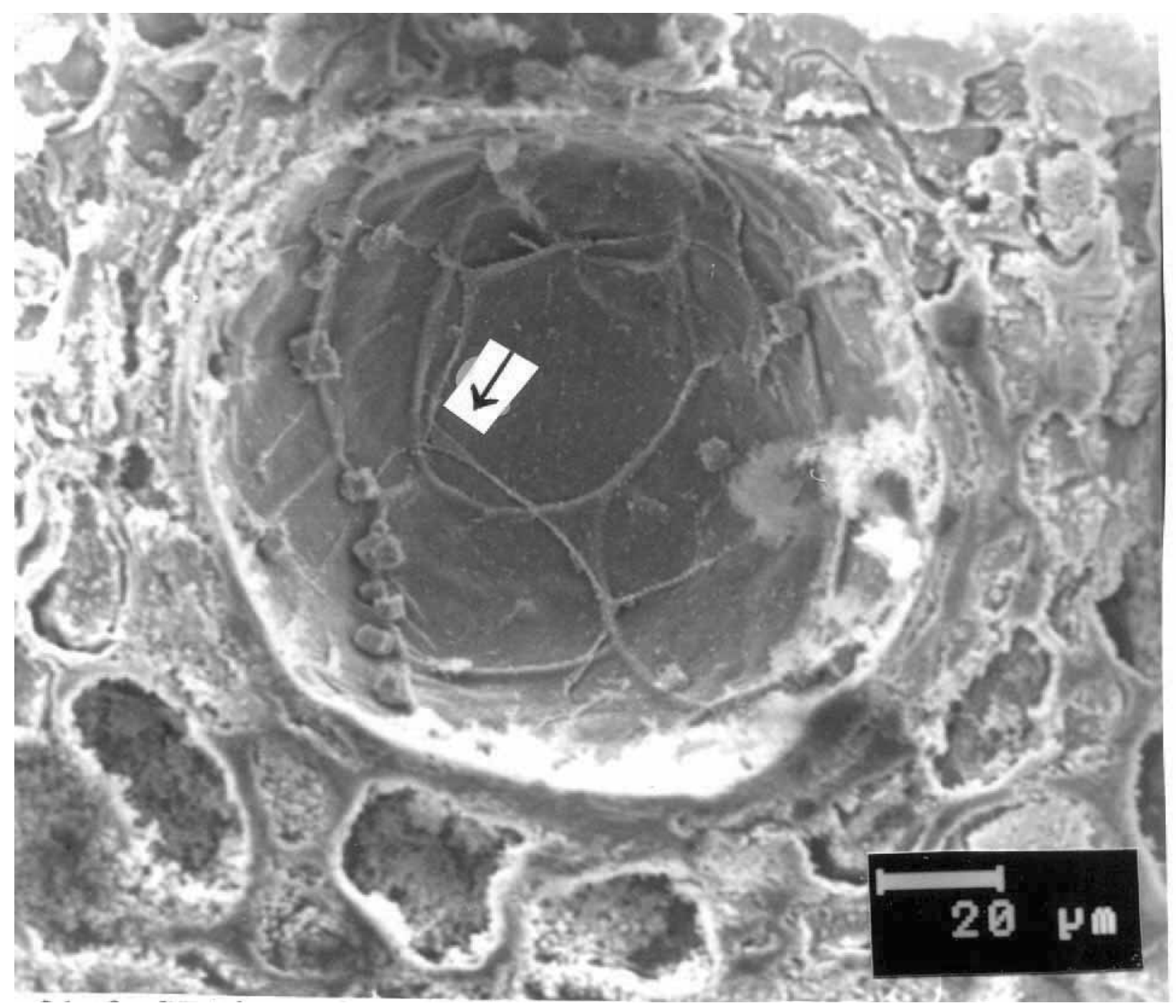

Figura 19. ST da região distal do pecíolo de Eugenia brasiliensis (restinga), em MEV, destacando uma cavidade secretora, na qual é visível o epitélio secretor (seta).

\section{REFERÊNCIAS}

Airy-Shaw HK, Willis's JC 1973. A Dictionary of the Flowering Plants and Ferns. 8 ed. England: Cambridge Univ. Press.

Arruda RCO, Fontenelle GB 1994. Contribuição ao estudo da anatomia foliar de Psidium cattleyanum Sabine (Myrtaceae). Rev Bras Bot 17: 25-35.

Barros CF 1998. Estudo da epiderme foliar de espécies tropicais. Rio de Janeiro, 175 p. Tese de Doutorado - Instituto de Biofísica Carlos Chagas Filho, Centro de Ciências da Saúde, Universidade Federal do Rio de Janeiro.

Barroso GM, Guimarães EF, Ichaso CF, Costa CG, Peixoto AL, Lima HC 1984. Sistemática de Angiospermas do Brasil. V 2. Viçosa: Imprensa Universitária da Universidade Federal de Viçosa.

Barroso GM, Peron MV 1994. Myrtaceae. In: Lima MPM, Guedes-Bruni RR (orgs.) Reserva Ecológica de Macaé de Cima - Nova Friburgo - RJ. Aspectos Florísticos das Espécies Vasculares. V 1. Rio de
Janeiro: Jardim Botânico do Rio de Janeiro, p.261302.

Barthlott W 1981. Epidermal and seed surface characters of plants: systematic applicability and some evolutionary aspects. Nord $J$ Bot 1: 345-355.

Bukatsch F 1972. Bemerkungen zur doppelfarbung astrablausafranin. Mikrokosmos 61: 225.

Callado CH 1993/1997. Anatomia foliar de Eugenia cuprea (Berg.) NDZ e Marlieria suaveolens Gard. (Myrtaceae). Rodriguesia 45/49: 25-37.

Carr DJ, Carr SGM 1970. Oil glands and ducts in Eucalyptus L’Hérit. II. Development and structure of oil glands in the embryo. Aust J Bot 18: 191-212.

Castro MM, Machado SR 2003. Células e tecidos secretores. In: Appezzato-da Glória B, Carmello-Guerreiro SM (eds). Anatomia Vegetal. Viçosa: Universidade Federal de Viçosa, p.179-203.

Cronquist A 1981. An Integrated System of Classification of Flowering Plants. New York: Columbia Univ. Press.

Dahlgren R, Thorne RF 1984. The order Myrtales: circuscription, variation and relationships. Ann 
Missouri Bot Gard 71: 633-699.

Duarte MR, Menarim DO 2006. Morfodiagnose da anatomia foliar e caulinar de Camellia sinensis (L.) Kuntze, Theaceae. Rev Bras Farmacogn 16: 545-551.

Eschrich W 1995. Funktionelle Pflanzenanatomie. Berlin: Springer-Verlag.

Ezequiel capítulo 47, versículo 12. In: Bíblia Sagrada. 158 ed. Edição Pastoral-Catequética. São Paulo: Ed. AveMaria.

Fahn A 1979. Secretory Tissues in Plants. London, New York: Academic Press.

Fernandez-Ferreira F, Ribeiro-dos-Santos R, Soares ROA, Branquinho LF, Ramos MFS, Henriques MGMO, Siani AC, Guimarães AC 1997. Avaliação da atividade de óleos essenciais de espécies de Myrtaceae e Burseraceae como agentes tripanossomicidas. III Jornada Paulista de Plantas Medicinais. CPQBA. UNICAMP.Campinas, Brasil.

Fevereiro PCA 1996. Aspectos botânicos. In: Bragança LAR. Plantas Medicinais Antidiabéticas. Uma abordagem multidisciplinar. Niterói: EDUFF.

Fontenelle GB, Costa CG, Machado RD 1994. Foliar anatomy and micromorphology of eleven species of Eugenia L. (Myrtaceae). Bot J Linn Soc 115: 111-133.

Foster AS 1949. Practical Plant Anatomy. Princeton: D. van Nostrand Company.

Gomes DMS 1992. Anatomia foliar de Gomidesia spectabilis (DC) Berg. e Gomidesia nitida (Vell.) Legr. Myrtaceae. Rio de Janeiro. Dissertação de Mestrado - Museu Nacional, Universidade Federal do Rio de Janeiro.

Hickey LJ 1979. A revised classification of the architecture of dicotyledonous leaves. In: Metcalfe CR, Chalk L (Ed.). Anatomy of the Dicotyledons. $2^{\text {nd }}$ ed. Oxford: Clarendon Press.

Howarth W, Warne LGG 1959. Practical Botany for the Tropics. London: University of London Press.

Johansen D 1940. Plant Microtechnique. New York: McGraw Hill Book.

Larcher W 2000. Ecofisiologia Vegetal. São Carlos: Rima.

Leite JPV, Pimenta DS, Gomes RSDL, Dantas-Barros AM 2007. Contribuição ao estudo farmacobotânico da Echinodorus macrophyllus (Kunth) Micheli (chapéude-couro) - Alismataceae. Rev Bras Farmacogn 17: 242-248.

List S, Brown PH, Walsh KB 1995. Functional anatomy of the oil glands of Melaleuca alternifolia (Myrtaceae). Aust J Bot 43: 629-641.

Machado JP 1992. Parque Nacional da Tijuca. Rio de Janeiro: Agir.

Machado RD, Costa CG, Fontenelle GB 1988. Anatomia foliar de Eugenia sulcata Spring ex Mart (Myrtaceae). Acta Bot Bras 1(Supl.): 275-285.

McLean RC, Ivimey-Cook WR 1958. Plant Science Formulae. $2^{\text {nd }}$ ed. London: Macmillan \& Co.

Menezes-de-Lima Jr O, Rosas EC, Henriques MGMO, Branquinho LF, Ramos MFS, Siani AC 1997. Avaliação da atividade antiinflamatória de óleos essenciais de espécies de Myrtaceae e Compositae. III Jornada Paulista de Plantas Medicinais.CPQBAUNICAMP. Campinas, Brasil.

Metcalfe CR, Chalk L 1950. Anatomy of the Dicotyledons. V 1. Oxford: Clarendon Press.
Meyer CP, Canny MJ 1975. CO² storage in Eucalyptus oil glands: a hypothesis disproved. Austral J Pl Physiol 2: 647-658.

Moreira F 1978. As plantas que curam. São Paulo: Hemus Livraria Editora.

Morretes BL 1967. Contribuição ao estudo da anatomia das folhas de plantas do cerrado. II. Boletim da Faculdade de Filosofia, Ciências e Letras da USP 22: 207-244.

Napp-Zinn K 1973. Anatomie des Blattes II. Blattanatomie der Angiospermen. In: Handbuch der Pflanzenanatomie. Spezieller Teil Bol 8 T 2 A, 2 fols. Berlin: Gebrüder Borntraeger.

Napp-Zinn K 1984. Anatomie des Blattes II. Blattanatomie der Angiospermen. Experimentelle und ökologische anatomie des Angiospermenblattes. In: Handbuch der Pflanzenantomie. Spezieller Teil. Band VIII, Teil 2 B. 2 fols. Berlin: Gebrüder Borntraeger.

Oliveira F, Akissue G 1989. Fundamentos de Farmacobotânica. Rio de Janeiro, São Paulo: Atheneu Ed.

Pio Corrêa M 1984. Dicionário das Plantas Úteis do Brasil e das Exóticas cultivadas. Rio de Janeiro: Imprensa Nacional.

Scopel M, Nunes E, Vignoli-Silva M, Vendruscolo GS, Henriques AT, Mentz LA 2007. Caracterização farmacobotânica das espécies de Sambucus (Caprifoliaceae) utilizadas como medicinais no Brasil. Parte I. Sambucus nigra L. Rev Bras Farmacogn 17: 249-261.

Siani AC, Branquinho LF 1997. Extração e análise química de óleos essenciais de espécies de Myrtaceae. VReunião de Iniciação Científica da Fundação Oswaldo Cruz. Rio de Janeiro, Brasil.

Siani AC, Ramos MFS, Rodrigues CM, Leite JP 1998 Atividade biológica de espécies da família Myrtaceae como agentes inibidores de rotavirus e astrovirus envolvidos na diarréia aguda. I Bienal de Pesquisa. Fundação Oswaldo Cruz. Rio de Janeiro, Brasil.

Solereder H 1908. Sistematic Anatomy of the Dicotyledons. V1. Oxford: Clarendon Press.

Souza MC, Lima-Júnior OM, Rosas EC, Ramos MFS, Siani AC, Henriques MGMO 1998. Efeito antiinflamatório de óleos essenciais de Eugenia jambolana Lam. e Psidium widgrenianum Berg. XV Simpósio de Plantas Medicinais do Brasil. Águas de Lindóia, Brasil.

Tunmann O 1909. Anatomische Utersuchung der Folia Eugenia apiculatae DC mit besondere Berücksichtigung der Sekretbehälter und der Trichome. 50, 886-895 (BZ113:271).

Tyrrel MH 1990. Evolution of natural flavor development with the assistance of modern technologies. Food Technol 44: 68-72.

Vieira S 1983. Introdução à Bioestatística. $2^{\mathrm{a}}$ ed. Rio de Janeiro: Ed. Campus.

Weaver JE, Clements FE 1929. Plant Ecology, apud Shields LM 1950. Leaf xeromorphy as related to physiological and structural influences. Bot Rev 16: 399-447.

Went F 1974. Reflections and speculations. Ann Rev Pl Physiol 25: 1-26. 